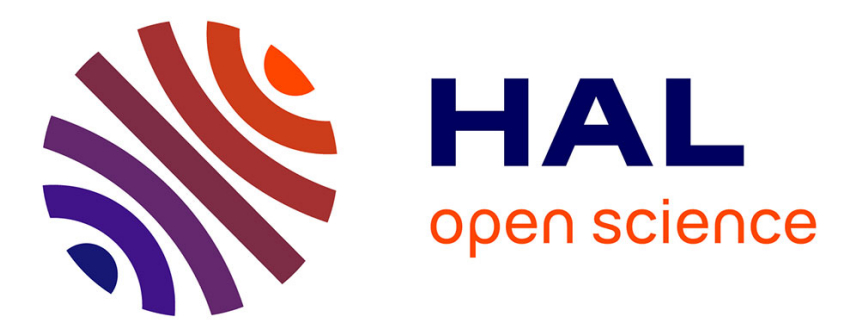

\title{
Autochthonous faecal virome transplantation (FVT) reshapes the murine microbiome after antibiotic perturbation
}

Lorraine A. Draper, Feargal J Ryan, Marion Dalmasso, Pat G. Casey, Angela Mccann, Velayudhan Vimalkumar, R. Paul Ross, Colin Hill

\section{To cite this version:}

Lorraine A. Draper, Feargal J Ryan, Marion Dalmasso, Pat G. Casey, Angela Mccann, et al.. Autochthonous faecal virome transplantation (FVT) reshapes the murine microbiome after antibiotic perturbation. 2019. hal-02163893

\section{HAL Id: hal-02163893}

https://hal-normandie-univ.archives-ouvertes.fr/hal-02163893

Preprint submitted on 24 Jun 2019

HAL is a multi-disciplinary open access archive for the deposit and dissemination of scientific research documents, whether they are published or not. The documents may come from teaching and research institutions in France or abroad, or from public or private research centers.
L'archive ouverte pluridisciplinaire HAL, est destinée au dépôt et à la diffusion de documents scientifiques de niveau recherche, publiés ou non, émanant des établissements d'enseignement et de recherche français ou étrangers, des laboratoires publics ou privés. 


\section{Autochthonous faecal virome transplantation (FVT) reshapes the murine microbiome after antibiotic perturbation}

Lorraine A. Draper ${ }^{1,2^{+}}$, Feargal J. Ryan ${ }^{1,2^{+}}$, Marion Dalmasso ${ }^{1,2,{ }^{*}}$, Pat G. Casey ${ }^{2}$, Angela McCann ${ }^{1,2}$, Velayudhan, Vimalkumar ${ }^{1,2}$, R. Paul Ross ${ }^{1,3}$, Colin Hill ${ }^{1,2 \#}$.

${ }^{1}$ APC Microbiome Ireland, University College Cork, Cork, Ireland.

${ }^{2}$ School of Microbiology, University College Cork, Cork, Ireland

${ }^{3}$ Teagasc Food Research Centre, Moorepark, Fermoy, Co. Cork, Ireland

*Present address: Normandie Univ, UNICAEN, ABTE, 14000 Caen, France

†Authors contributed equally to this work

\# Corresponding Author

Colin Hill-email: c.hill@ucc.ie 


\section{Abstract}

Background: It has become increasingly apparent that establishing and maintaining a complex and diverse gut microbiome is fundamental to human health. There are growing efforts to identify methods that can modulate and influence the microbiome, especially in individuals who due to disease or circumstance have experienced a disruption in their native microbiome. Faecal microbial transplantation (FMT) is one method that restores diversity to the microbiome of an individual by introducing microbes from a healthy donor. FMT introduces a complete microbiome into the recipient, including the bacteriome, archaeome, mycome and virome. In this study we investigated whether transplanting an autochthonous faecal virome consisting primarily of bacteriophages could impact a bacteriome disrupted by antibiotic treatment (Faecal Virome Transplantation; FVT).

Results: Following disruption of the bacteriome by penicillin and streptomycin, test mice $(n=8)$ received a bacteria free, faecal transplant, while Control mice $(n=8)$ received a heated and nuclease treated control. The bacteriomes (as determined via 16S rRNA sequencing) of mice that received an FVT, in which bacteriophages predominate, separated from those of the Control mice as determined by principle co-ordinate analysis (PCOA), and contained differentially abundant taxa that reshaped the bacteriome profile such that it more closely resembled that of the pre-treatment mice. Similarly, metagenomic sequencing of the virome confirmed that the bacteriophages present in the gut of treatment and Control mice differed over time in both abundance and diversity, with transplanted phages seen to colonise the FVT mice.

Conclusions: An autochthonous virome transplant impacts on the bacteriome and virome of mice following antibiotic treatment. The virome, consisting mainly of bacteriophages, reshapes the bacteriome such that it more closely resembles the pre-antibiotic state. To date, faecal transplants have largely focussed on transferring living microbes, but given that bacteriophage are inert biological entities incapable of colonising in the absence of a sensitive host they could form a viable alternative that may have fewer safety implications and that could be delivered as a robust formulation.

\section{Keywords}

Bacteriophage; Virome; Transplantation; Microbiome; Antibiotic; Murine; Bacteriome. 


\section{Background}

The mammalian gastrointestinal tract is home to a complex and intimately associated microbial ecosystem (microbiome), comprised of bacterial (bacteriome), archaeal (archaeome), fungal (mycome) and viral (virome) components. The virome is mainly composed of bacteriophages (bacterial viruses collectively referred to as the phageome). It has been estimated that the human gut can contain as least as many bacteriophages as there are bacteria $\left(10^{14}\right)[1-3]$, making it perhaps the most densely populated ecological niche in nature. Co-evolution over millennia has selected those members of the microbiome that either cause no harm or confer a benefit to the host, these are commonly referred to as the commensals and mutualists of the gut [4-6]. A healthy microbiome is also associated with high bacterial strain level diversity [7] and bacteriophage may play an important role by restricting overgrowth of the most successful strains in 'kill the winner' dynamics. If phages have the potential to modulate the gut bacteriome, then in turn they could have an impact on host-microbe interactions and on host health [8]. Mammalian hosts have evolved to rely on microbial activities to assist digestion, provide vitamins, resist pathogens, and to regulate metabolism and the immune system [9] [10]. The intestinal microbiome is also a potent source of antigens and potentially harmful compounds [11]. Obtaining an appropriate microbiome at birth, and subsequently developing and maintaining it in the face of challenges such as antibiotic therapy, is an important determinant of health and wellbeing [12].

A multitude of studies have identified alterations in gut microbiomes in a wide variety of diseases, such as inflammatory bowel disease (IBD) including Crohn's disease, activation of chronic human immunodeficiency virus (HIV) infection, atopy and a variety of psychological disorders, to name but a few [13-18]. Modernisation of society has impacted on microbiome diversity in many ways, including factors such as urbanization, global mobility, improved sanitation and hygiene, consumption of highly processed diets, non-familial child care, less contact with animals and medical therapies. It is likely that the ancestral relationship between a diverse gut microbiome and its human host has essentially been surpassed by the speed of invention and technology. A recent study that investigated the microbiome of the uncontacted Yanomami Amerindian people allows us a glimpse into the past. It appears that traditional lifestyles enabled the human gut to harbour a microbiome with high 
bacterial diversity and genetic function, something that has been compromised by modern lifestyles [19].

Antibiotics can be considered to be just one of these aspects of modernization and serves as an example of how essential medical therapies can lead to perturbations in the gut ecosystem, a situation exacerbated by misuse of antibiotics. Antibiotics have served as the initial line of defense against pathogenic bacteria for decades. The mass production of penicillin in the 1940s revolutionised modern medicine, ending a world where patients commonly died from bacterial endocarditis, bacterial meningitis, and pneumococcal pneumonia. Broad spectrum antibiotics have saved millions of lives but may leave the gut microbiome in an altered state in which the delicately constructed ecosystem of the gastrointestinal tract may be compromised.

Probiotics [20-22], prebiotics and other dietary interventions have been investigated [23] as tools to ameliorate the negative aspects of antibiotic use. The most radical therapy is faecal microbial transplantation (FMT), whereby the microbiome of an individual is supplemented by that of healthy donor [24]. In human therapy, FMTs are usually confined through practitioner guidelines to those suffering from severe, moderate or recurring $C$. difficile infections [25]. However, while case reports of FMT in patients with ulcerative colitis and Crohn's disease are variable, some report that a certain percentage of patients achieve and can even maintain remission in some instances [26]. FMT has also been suggested as a potential therapy in irritable bowel syndrome, Type 2 diabetes mellitus, metabolic syndrome, obesity, fatty liver disease, multidrug resistant organism eradication, hepatic encephalopathy and paediatric allergy disorders [24].

With a standard FMT, the entire stool is homogenised and filtered through gauze and the resulting preparation is then infused into the gut. The entire microbiome is introduced into the recipient, including bacterial, archaeal, fungal and viral species. In this study we investigated if autochthonous virome transplantation (in which bacteriophage predominate) can impact on the bacteriomes and phageomes of mice following disruption with antibiotic treatment. 


\section{Results}

\section{Sequencing of the murine bacteriome}

Two separate trials (designated as Study 1 and Study 2) were performed. In both trials $16 \mathrm{~S}$ rRNA gene sequencing was used to determine the composition of the faecal bacteriome of pre- and post-antibiotic treated mice $(n=16)$. Half of the mice subsequently received an FVT $(n=8)$ or a heat-treated FVT as a control $(n=8)$. Virome transplantation was conducted using a bacteria free-virus faecal filtrate collected from the same mice prior to antibiotic treatment. In Study 1, a single gavage was performed after antibiotic washout, while in Study 2 a second gavage was also performed 4 days later (see experimental design in Fig S1). MiSeq (V3 kit - $300 \mathrm{bp}$ paired end reads) sequencing resulted in an average of 16,805 \pm 8,079 (Study 1) or 31,758 $\pm 64,605$ (Study 2) paired end reads across the samples; and an average of $14,514 \pm 7,095$ (Study 1) or $29,350 \pm 59,214$ (Study 2) individual reads postquality filtering (Supplementary Tables S1 and S2).

\section{Impact of antibiotics on the murine gut bacteriome}

After a period of acclimatisation, mice were administered an antibiotic cocktail of penicillin and streptomycin in their drinking water for either four days (Study 1), or two days (Study 2). Following antibiotic treatment (CTAb) a significant change occurred in the murine bacteriome as compared to pre-treatment mice (samples at СТ000 and СТ00). These differences can be visualised via unweighted UniFrac PCoA (principal co-ordinate analysis; Fig 1 A), as well as via weighted UniFrac and Bray Curtis PCoA (Fig S2).

Using the Shannon index as a measure of alpha diversity it is apparent that the bacterial diversity decreased after antibiotic treatment in both studies. In Study 1 (Fig S3A), after 4 days of antibiotic treatment (CTAb) there is a lower Shannon diversity than that observed for CTAb in Study 2 (Fig S3B), which is in consistent with a shorter two-day administration of antibiotics. However, when we examine bacterial cell numbers (log 16S copies/gram of faeces; Figure S4) there was a greater reduction in cell numbers in Study 2, when antibiotics were only administered for half the time (Study 1: log (16S copies/gram of faeces) mean 9.45; median 9.93; and Study 2: mean 7.80; median; 7.49). It must be noted however that in Study 2 the alpha diversity decreased further than that observed for the CTAb sample in the Control and FVT Mice in the T1 samples, and concomitantly bacterial numbers were elevated (Control mice T1: mean 8.56; median 8.76; and FVT Mice T1: mean 9.08; median 
9.25) as was observed for Study 1-CTAb, where the lowest Shannon diversity of this study was also observed.

The increase in bacterial cell numbers may correlate with the outgrowth of certain species (Fig S5). For example, in Study 1 we observed an increase in E. coli/Shigella species in the antibiotic treated mice that continued to increase in the post gavage mice (CT1/VT1). After the shorter exposure to the antibiotic treatment in Study 2, this out-growth of E.coli/Shigella species was only observed in the faeces of the 10hr post-gavage (CT1/VT1) mice. In the CTAb mice, we did however observe an increase in "Other" species (those RSVs unclassified to genus level) and a decrease in Alistipes, Bacteroides and Barnesiella species. Classification of RSVs to a phylum level ascribes these changes to a decrease in Bacteroidetes and Firmicutes, and an increase in Actinobacteria, Proteobacteria, Cyanobacteria and unclassified others.

\section{The impact of bacteriophage on the antibiotic treated murine gut bacteriome}

\section{Study 1}

Following antibiotic treatment mice were divided into two groups $(n=8)$ and received a gavage of either autochthonous viable (FVT) or heat-treated bacteriophages (Control) by means of a faecal filtrate. In Study 1 the inferred PCoA plots of unweighted Unifrac distances (Fig 1A) we observe separation of the bacteriomes of Control and FVT mice into different clusters that both gradually return to a location similar to that of the pre-antibiotic bacteriome. Eleven days post-gavage there is a significant difference in the bacteriomes of FVT and Control groups as revealed by Adonis PERMANOVA analysis ( $\mathrm{P}$-value $=0.004)$. These differences were also observed using Bray Curtis distances but not using weighted Unifrac (Fig S2A, Table S3).

Differentially abundant taxa were also identified between the FVT and Control groups 11 days post-gavage (Fig 3A). Twelve RSVs were statistically distinct in their abundance (Table S4). Of these 12, six belong to the family Lachnospiraceae, while Ruminococcaceae accounted for one, as did Porphyromonadaceae and Deferribacteraceae. The final three were unclassified to the family level but are of the Order Clostridiales. Interestingly, all 12 RSVs not only differed in their abundance between CT4 vs VT4 mice but all are statistically different in their abundance compared to the pre-treatment mice (Ст00). With 10 of these 
RSVs increased in Control mice (that did not receive viable phage), it implies that the FVT aided in restoring the murine bacteriome to its pre-treatment state. The RSVs increased in Control mice were of the predominantly of the family Lachnospiraceae, the remainder included the species Mucispirillum schaedleri and Parabacteroides goldsteinii. Only two RSVs were increased in mice receiving phage and these belong to the families Lachnospiraceae and Ruminococcaceae and include the species Eubacterium siraeum.

\section{Study 2}

Study 1 demonstrated that administration of a bacteriophage enriched gavage can impact the murine microbiota and so we performed a second more comprehensive study. Here a second antibiotic gavage was administered 4 days after the first and an increased number of samples (including caecum content) were analysed.

In Study 2, PCoA plots (Unweighted Unifrac, Bray Curtis and Weighted Unifrac (Fig 2A and S2B)) display clear clustering of RSVs defined by whether they received heat killed or viable phage. As in Study 1, over time the bacteriome of the mice gravitates from the postantibiotic treatment state (CTAb) to the pre-treatment state (СТ0O \& СTO00). We observed separation of the microbiota of mice into significantly different clusters from four days postGavage 2 (T4) to the end of the experiment (T6), where these differences were also revealed in the ceca (CeT6) (Adonis PERMANOVA: T4 P-value $=0.002$, T5 P-value $=0.001$, T6 P-value $=$ 0.001, CeT6 P-value $=0.001)($ Fig 2B). These differences were also observed using Bray Curtis distances but not in the case of weighted Unifrac (Fig S2B, Table S3).

Alpha diversity confirms a clear increase in diversity post-antibiotic treatment in both control and FVT receiving mice (Fig S3B). Several differentially abundant taxa were observed between CT4 and VT4 (13 RSVs), CT5 and PT5 (51 RSVs), CT6 and PT6 (37 RSVs) and CceT6 and PceT6 (25 RSVs) (Table S5). 26 RSVs were noted to be differentially abundant across two or more time points and five were highlighted to be differentially abundant at T6 in both faeces and caecum, revealing that these core taxa are more directly influenced by the presence or absence of administered bacteriophages. With respect to these 31 RSVs the taxa were almost equally distributed between Bacteroidetes (52\%) and Firmicutes (48\%). At the family level Porphyromonadaceae (36\%) and Lachnospiraceae (32\%) predominated. Lactobacillaceae accounted for a further $7 \%$ of RSVs, while Rikenellaceae and 
Ruminococcaceae accounted for $6 \%$ and $3 \%$, respectively. The most commonly assigned genus was Barnesiella at 16\%; however, $65 \%$ of RSVs could not be assigned to the genus level. Of the Barnesiella identified $75 \%$ were classified to be of the species Barnesiella intestinihominis.

A volcano plot was used to visualise the differential association of RSVs across the time points T4, T5, T6 and in the caecum at T6 (Fig 3B). Firmicutes family members (red hues) are more abundant in FVT animals across the final two time points and in the caecum, while Bacteroidetes family members (blue hues) are more abundant in Control mice. If we compare the faecal Firmicutes-Bacteroidetes ratio with pre-treatment (СТ00) mice, we observe a significant decrease in this ratio in both sub-sets at T4. This ratio decreases further in Control mice at T6 while those that received bacteriophage return to that observed for pre-treatment mice at T6 (Kruskal-Wallis with Dunn's multiple comparison post-test; CT00 vs CT4/VT4: P-value <0.05; CT00 vs CT6: P-value <0.01; СT00 vs VT6: P-value $>0.05$ ) (Fig 4).

Further examination revealed that certain taxa remain increased in FVT or Control mice over time (Table S5). For example, RSV_8 belonging to the family Porphyromonadaceae can be seen to fluctuate in abundance across the three faecal times points represented here, but is consistently increased in Control mice. All differentially abundant RSVs as determined by DESeq2 were compared to the abundance of these same RSVs in pre-treatment mice. Of the differentially abundant taxa at T4, 31\% of the RSVs increased in FVT mice differed in their abundance as compared to pre-treatment (СТО0) mice, while only $23 \%$ of differentially abundant RSVs in Control mice differed from pre-treatment mice. Over time these percentages decrease in bacteriophage-receiving FVT mice with only $10 \%$ at T5 and $5 \%$ at T6 of the RSVs differing in their abundance from CTOO mice, while in Control mice the opposite is observed with $12 \%$ at T5 and $54 \%$ at T6 (Supplementary table S5-RSVs that differ from СT00 mice are highlighted in blue).

\section{Murine viromes}

In addition to examining the impact of bacteriophages on the murine bacteriome, we also performed a metagenomic study on DNA isolated from viruses extracted from the murine faecal samples. Technical limitations involving virome yield meant that the results represent the viromes of groups of mice rather than individual animals, in that faecal samples were 
pooled for pre-treatment $(n=16)$, antibiotic treated $(n=16)$, control $(n=8)$ and FVT treated mice $(n=8)$ at each time point (Fig S1). The virome data was analysed utilising an assembly based approach. Notably the viral sequences assembled here are not represented in current databases.

The virome that made up the FVT gavage can now be visualised as being present in the СТ000 and СТ00 samples (Fig 5). In both studies the virome composition differs between control and FVT mice in the post-gavage samples. Moreover, 11 days post antibiotic treatment those mice that received an FVT retain a notable abundance of the bacteriophages introduced in the gavage. For example, in Study 1 APC-pVirus10 is found in V-VT4 mice but is absent from the corresponding control V-CT4; in Study 2 APC-pVirus9 and APC-pVirus21 are found in abundance in V-VT6 mice where they are all but diminished in the control.

In conjunction with the outgrowth of $E$. coli/Shigella post-antibiotic treatment, we detected an increase in the abundance of APC-pVirus2. This is particularly noticeable in Control mice (V-CT1) that did not receive a viable FVT compared to those in receipt of FVT (V-VT1) (Fig 5 and Fig S5). Moreover, one putative bacteriophage APC-pVirus15 appears to be increased in abundance in the gut of Control mice compared to their FVT-receiving counterparts at corresponding time points. This is observed in both Study 1 and Study 2, suggesting the presence of particular bacterial hosts, common in these control animals, are facilitating replication of this bacteriophage.

Within the individual studies, we have reported that at specific time points differentially abundant bacterial taxa were detected. In Study 1, we observed that in the final time point (where such differentially abundant bacterial taxa were observed) that the phageomes of control and FVT mice differ not only in content but also in their corresponding relative abundances. A total of 152 bacteriophages were identified in the eight Control mice at this time point, while 163 are associated with FVT-receiving mice (Fig 5). With respect to viral abundances at this final time point, APC-pVirus11 and APC-pVirus15 constitute the majority of the viral load of Control mice, while APC-pVirus26 predominates in the gut of FVT mice. In Study 2, where 2 sequential gavages of viable FVT were administered, the variability in the profiles of the putative bacteriophages present and their relative abundances between control and FVT animals appears to differ even more. The richness of viral diversity is also elevated in FVT mice, especially in the final time points in tandem with the observation of 
differentially abundant bacterial taxa. This equates to a $20-30 \%$ increase in specific bacteriophages in these animals up to 11 days post gavage (see supplementary table S5). It must be noted however that these results are based on a pooled sample and so no statistical conclusions can be drawn.

\section{Discussion}

The impact of externally added phages on GI tract bacteria has been studied for 100 years. d'Herelle in 1919 used a phage preparation to treat dysentery in what was almost certainly the first attempt to use bacteriophages therapeutically [42]. Since then there have been multiple studies revealing the impact of phage on a range of Gl pathogens [for reviews see 8, 43-45]. Intestinal bacteriophages are likely to influence and shape the microbial ecology of the mammalian gut, similar to that observed in aquatic systems where it has been proposed that phages are responsible for $20-80 \%$ of total bacterial mortality and play a significant role in limiting bacterial populations [2, 46]. Bacteriophages have a profound impact on microbial population dynamics and are one of the driving forces shaping the functionality and diversity of the human intestinal microbiome [reviewed in 2].

Here we report on how the administration of an autochthonous FVT had a significant impact on the bacteriome of mice following antibiotic-induced disruption. The bacteriome and phageome of FVT-receiving animals differed in the abundance and/or diversity of species. While the benefits of faecal transplantation have been well documented, the impact of bacteriophage within this microbial community has yet to be fully investigated. The transfer and long-term colonisation of bacteriophages species during standard FMT has been documented [47], with temperate phage members of Siphoviridae found to be transferred between human donors and recipients with significantly greater efficiency than other bacteriophage groups [48]. Bacteriophages may well be important elements of FMT that can influence and shape gut ecology. One study has in fact indicated that a sterile filtered faecal transplant (FFT), where cellular microbes were removed, produced longitudinal changes in the bacterial and viral community structures of faecal samples in five human recipients suffering from Clostridium difficile infections, all of whom recovered following treatment [49]. The potential role of bacteriophage in the recovery of the microbiota from the ravaging 
effects of this infection was acknowledged, along with potential roles for bacterial components and metabolites.

In the two studies described here, we disrupted the murine microbiome with antibiotics prior to administration of autochthonous bacteriophage. These antibiotics have a broad spectrum of activity. Streptomycin is an aminoglycoside inhibitor of protein synthesis that binds primarily to $16 \mathrm{~S}$ ribosomal RNA and inhibits both Gram-positive and Gram-negative bacteria. Penicillin is a $\beta$-lactam inhibits cell wall biosynthesis and targets Gram-positive species. These antibiotics have also been shown to exhibit synergistic activity [50, 51]. Previous studies have shown that treatment of mice with streptomycin increases susceptibility to oral infection with Salmonella enterica serovar Typhimurium [52]. After antibiotic treatment we observed an outgrowth in E. coli/Shigella species that coincided with low $\alpha$-diversity and elevated bacterial cell numbers. Such outgrowth could be linked with antibiotic insensitivity of these species allowing them to dominate their more sensitive relatives. This has been described for $E$. coli in a number of studies $[53,54]$. The occurrence of these elevated levels of $E$. coli varies across the two studies and perhaps can be attributed to deviations in the length of antibiotic treatment pre-sampling.

Following the administration of a single FVT gavage in Study 1, we witnessed an alteration in the faecal bacteriome in PCoA plots and via the presence of differentially abundant taxa at the final time-point. This impact re-shaping of the gut bacteriome was also observed, and to a greater extent, during Study 2 where the bacteriophage dose was doubled by means of sequential gavages four days apart. In Study 2 differentially abundant taxa were observed across the final three time-points and also in the ceca. Samples derived from the murine caecum have a bacteriome composition distinct from that of the faecal samples [55]. Therefore, differences observed here between phage treated and Control mice indicates alterations in the bacteriome at multiple GI sites and infers that the impact of bacteriophage on the murine gut is widespread.

Each gram of human faeces contains approximately $10^{11}$ bacterial cells, $10^{11}$ bacteriophages, $\sim 10^{7}$ colonocytes, $\sim 10^{8}$ archaea, $\sim 10^{8}$ viruses, $\sim 10^{6}$ fungi, protists and metabolites [56-58]. The protocols used to process the murine faeces used to prepare the FVT gavage in this study would have removed all biological species apart from bacteriophages and viruses (and those metabolites or microbial structures are also present 
in the control gavage). Heat inactivation of bacteriophage and the use of nucleases ensures that the Control mice would have only received small-molecule metabolites, bacterial components or antimicrobial compounds of bacterial origin (e.g. bacteriocins) that contribute to the normal intestinal microenvironment. Thus, we can deduce that the alterations to microbiome (both bacteriome and virome) of test mice is due to the acquisition of viable bacteriophages.

Of the differentially abundant RSVs identified, a subset were annotated as the species Barnesiella intestinihominis, which appeared on multiple occasions to be present in greater abundance in Control mice (Study 2 - T4, T5, T6 and caecum T6). This Gram-negative commensal bacterium has been classified as an oncomicrobiotic for its immunomodulatory properties [59]. Loss of this species in FVT-receiving mice suggests that they obtained a bacteriophage that could utilise $B$. intestinihominis as a host, thus diminishing the population of this species. This is described as the "kill the winner" model, but what also may be the case is the "kill the relative" model, whereby the induction or presence of prophage/lysogenic bacteriophages can trigger an epidemic among susceptible bacterial competitors [57]. Several other models that describe how bacteriophage can shift the dynamic of bacterial populations also exist. One model of interest and relevance to this study is the "community shuffling model", which involves the induction of prophage and stimulation of the host immune system by environmental factors [57] such as sub-inhibitory levels of antibiotics, such as quinolones or beta-lactams (as was utilised here albeit at inhibitory levels) from bacterial species such as E. coli [60], Clostridium difficile [61], E. faecalis [62] and Staphylococcus aureus [63]. Should the presence of antibiotics within the current studies have encouraged such events, it should have occurred prior to administration of exogenous bacteriophages and so would have been present in both control and test animals. These prophages could however have contributed to the bacteriophage profile present in CTAb mice and to the initial ecology to which the administered FVT was introduced.

Given that the FVT treated mice had a distinct bacteriome, we were able to identify a number of differentially abundant bacterial taxa and these could be visualised on volcano plots. Via colour coding of family members, it became apparent that there was a clear shift in favour of Firmicutes family members in those that received bacteriophages. This may indicate that these mice did not have or receive bacteriophages that target these family 
members, in particular the Lachnospiraceae. Alternatively, there may be other population dynamics models at play such as those mentioned previously. Conversely, in Control mice such bacteriophage either flourished or the ecological conditions of the gut were so that members of the Bacteroidetes family predominated. Firmicutes-Bacteroidetes ratios confirmed that this phenomenon was not confined to differentially abundant taxa but was statistically valid across all reads.

When we examine how the presence/absence of differentially abundant bacterial taxa compare to these same RSVs in pre-treatment mice after acclimatisation (CTOO), we observed that the bacteriome of FVT mice more closely resembles that of CTOO mice than that of the Controls. This indicates that autochthonous bacteriophages have impacted and shaped the bacteriome, restoring it to a pre-treatment state. By killing bacteria, bacteriophages implement population fluctuations in their bacterial hosts, they significantly influence global biochemical cycles, and are also considered to be crucial in driving microbial species diversity due to the fact that they are species-specific $[64,65]$.

Within these studies we pooled faecal matter from СT000 and СT00 mice (pre-antibiotic treatment) and created a sterile autochthonous faecal virome for transplantation. We used metagenomic DNA sequencing and assembly of the resulting contigs to determine the bacteriophage content. In both studies, FVT mice appeared to retain the bacteriophage they received up to 11 days post gavage, long after the transit time of several hours noted for bacteriophage through the Gl tract [66]. While we cannot draw any statistical conclusions since we only had a single autochthonous combined faecal sample for each group, our observations mirror those observed by Ott et al., 2016 [49] in humans that received an FFT, with the recipient virome altering substantially and retaining features of the FVT sample.

Gut bacteriophages are so numerous and diverse that sequence databases contain only a small fraction of the total diversity [67-69], and so we used an assembly approach to identify these bacteriophages rather than relying on annotation via alignment to public databases. Of the bacteriophages identified here, none are currently present on public viral databases, we propose that this assembly approach opens the door to discovery of unknown bacteriophages and viruses whose impact and influence in the microbiome could go unnoticed simply due to the paucity of current viral databases. 


\section{Conclusions}

To our knowledge this is the first time that an autochthonous FVT has been shown to remodel and restore the mammalian gut following a period of microbial disruption. While others such as Ott et al, 2016 have suggested the role of bacteriophage in human FFT (fecal filtrate transplant; [49]), this study with the inclusion of a control treatment has validated a role for bacteriophage in microbiome population dynamics. There is potential to take advantage of this observation, especially with the increasing trend toward performing FMTs. Until now these have largely focussed on transferring living bacteria and spores; but bacteriophage are non-living proteinaceous entities that could form a robust, inexpensive alternative that could be delivered as a freeze dried formulation.

\section{Methods}

\section{Mouse models and experimental design}

Study1:

16 BALB/C mice were obtained from Harlan Laboratories UK Ltd. and were housed within the Biological Services Unit, University College Cork (UCC). Mice were received at 7-8 weeks of age and allowed to acclimatise for 5 days on a standard rodent diet. During this time faecal samples were collected, frozen $\left(-80^{\circ} \mathrm{C}\right)$ and used, in part, to prepare FVT phage-rich material which will be used for oral gavage. This required obtaining $2-3 g$ of faecal pellets which were resuspended in a solution of $10 \mathrm{ml}$ filter sterilised SM buffer $(50 \mathrm{mM}$ Tris- $\mathrm{HCl}$; $100 \mathrm{mM} \mathrm{NaCl} ; 8.5 \mathrm{mM} \mathrm{MgSO}_{4} ; \mathrm{pH} 7.5$ ) and $2 \mathrm{ml} 1 \mathrm{M} \mathrm{NaHCO}_{3}$ (to help deacidify the stomach). After vortexing, the solution is centrifuged at $4700 \mathrm{rpm}$ for 20 mins. The supernatant was then filter sterilised $(0.45 \mu \mathrm{M}$ filter) and divided into 2 separate containers. One to be administered to the test (FVT) group and contains active bacteriophages/viruses, while the second was heated at $95^{\circ} \mathrm{C}$ for 15 mins, followed by DNase (Ambion) treatment at $37^{\circ} \mathrm{C}$ for 1 hr (according to manufacturer's guidelines) as described by Reyes et al [27], and thus contained inactivated bacteriophages to be administered to the control group. After acclimatisation, all 16 mice were administered antibiotic treatment (penicillin 1000U/ml and streptomycin $3 \mathrm{~g} / \mathrm{L}$ ) in their drinking water for 4 days (and faecal samples were collected) followed by 1 day of antibiotic wash-out, where standard drinking water was administrated 
ad libitum. Following this, the mice were divided into 2 groups $(n=8)$, faecal samples were collected and the FVT group were gavaged with $0.2 \mathrm{ml}$ of the FVT material (as prepared above) while the control group received inactivated bacteriophages. Faecal samples were then collected $10 \mathrm{hr}, 24 \mathrm{hr}, 34 \mathrm{hr}$ and 11 days afterward.

\section{Study 2:}

Study 2 was performed as that described for Study 1 with the following deviations. 16 $\mathrm{BALB} / \mathrm{C}$ mice were received at 8-10 weeks of age and allowed to acclimatise for 3 days. After acclimatisation, all 16 mice were administered antibiotic treatment (penicillin 1000U/ml and streptomycin $3 g / L$ ) in their drinking water for 2 days followed by 1 day of antibiotic washout. Following this, the mice were divided into 2 groups $(n=8)$, faecal samples were collected and the FVT group were gavaged with $0.2 \mathrm{ml}$ of active bacteriophages (as prepared above) while the control group received inactivated bacteriophages ("Gavage 1"). Faecal samples were then collected 1 and 4 days afterward. Forthwith a second gavage ("Gavage 2") was subsequently administered in a similar manner as described for Gavage 1. Again faecal samples were collected from both groups post-gavage at 1, 4, 7 and 14 days. Post-mortem, caecum content was also collected.

\section{DNA extractions and library preparation for MiSeq}

Faecal samples were all frozen immediately after collection at times indicated in Fig S1 and then used to extract bacterial DNA for $16 \mathrm{~S}$ rRNA analysis of the bacteriome $(\sim 2-5$ faecal pellets were collected from each mouse at each time point and used track alterations in the bacteriome of each individual mouse). The QIAamp DNA Stool Mini Kit (Qiagen, Hilden, Germany) was used according to manufacturer's guidelines to extract bacterial DNA but was modified to include a bead-beating step. 16S ribosomal DNA hypervariable regions V3 and V4 were amplified via PCR using a high fidelity polymerase (Phusion; Thermo Fisher Scientific) and the primers V3F - 5'-CCTACGGGNGGCWGCAG-3' and V4R - 5'GACTACHVGGGTATCTAATCC-3' [28] with the addition of the appropriate Illumina Nextera XT overhang adapter sequences (Illumina, San Diego, CA, USA). Following purification using a magnetic bead capture kit (Ampure; Agencourt), the amplicon libraries underwent a second PCR reaction to attach dual indices and Illumina sequencing adapters using the 
Nextera XT index kit (Illumina, San Diego, CA, USA). Following purification (as described above) the dsDNA libraries were quantified using a Qubit ${ }^{\circledR}$ Fluorometer (Thermo Fisher Scientific) were then pooled in equimolar concentrations. Ready to load libraries were sequenced on an Illumina MiSeq (Illumina, San Diego, California) using V3 sequencing kit (300 bp paired end reads) at GATC Biotech AG, Germany.

\section{Analysis of $16 \mathrm{~S}$ sequencing data}

The quality of the raw reads was visualized with FastQC v0.11.3. T Forward and reverse reads in were merged using FLASH [29] Primers were removed from the merged reads using the fastx_truncate command of USEARCH [30]. The trimmed reads were then demultiplexed with a Phred quality score of 19 using the split_libraries_fastq.py script of the QIIME package [31]. The demultiplexed sequences in FASTA format were then de-replicated using the derep_fulllength command of USEARCH and sequences below a minimum length cutoff (400nt) were removed. Singletons were removed using the minsize option of the sortbysize command of USEARCH. The resulting sequences were then clustered into OTUs using the cluster_otus command and then chimera filtered using both the de novo and reference based chimera filtering implemented in USEARCH with the ChimeraSlayer gold database v20110519 [30] The reads were then aligned back to the OTU's using the usearch_global command of USEARCH to generate a count table which was input into $R$ for statistical analyses. Taxonomy was assigned to the sequences using mothur v1.38 [32] against the RDP database version 11.4, as well as classified with SPINGO to species level [33]. Only ribosomal sequence variants (RSVs) with a domain classification of Bacteria or Archaea were kept for further analysis. A phylogenetic tree of the RSV sequences rooted on the midpoint was generated with FastTree [34]. Alpha diversity and Beta diversity were generated using PhyloSeq v1.16.2, which also was used for a principle coordinates analysis as implemented in Ape v3.5. Differential abundance analysis was carried out with DESeq2 v1.12.4[35]. All visualisation in R was performed with ggplot2 v2.2.1. Permutational multivariate analysis of variance (PERMANOVA) was performed in R Vegan package with the adonis function (Model formula = antibiotic treatment timepoint + Phage/control status) with 9999 permutations. 
bioRxiv preprint first posted online Apr. 2, 2019; doi: http://dx.doi.org/10.1101/591099. The copyright holder for this preprint (which was not peer-reviewed) is the author/funder, who has granted bioRxiv a license to display the preprint in perpetuity. All rights reserved. No reuse allowed without permission.

\section{Real-time qPCR}

A LightCycler ${ }^{\circledR} 480$ apparatus (Roche), associated with LightCycler ${ }^{\circledR} 480$ Software (version 1.5; Roche), was used for the real-time PCR. Each reaction contained a $5 \mu$ l of a 1 in 10 dilution of genomic DNA and was carried out in quadruplicate in a volume of $15 \mu \mathrm{l}$ in a 384well LightCycler ${ }^{\circledR} 480$ PCR plates (Roche), sealed with LightCycler ${ }^{\circledR} 480$ sealing foil (Roche). Amplification reactions were carried out with Phusion $2 \mathrm{X}$ master mix (Thermo Fisher Scientific) using run conditions, primers $(0.5 \mathrm{pmol}$ each per reaction) and probe $(0.1 \mathrm{pmol}$ per reaction) as described by Furet et el [36]. Quantitation was done by using standard curves made from known concentrations of linearized plasmid DNA containing the $16 \mathrm{~S}$ amplicon. Wells containing nuclease free water were included as negative controls. Statistical analysis was performed using Graphpad Prism 5, whereby a One-Way ANOVA followed by Tukey test determined statistical significance; ${ }^{* * * P}$ value $<0.001, * * P$ value $<0.01, * \mathrm{P}$ value $<0.05$.

\section{Virome DNA extraction and library preparation for MiSeq}

DNA corresponding to the viromes of each group of mice was purified from faecal samples, with approximately 1 pellet per mouse included in the extraction. Samples were taken at the time points indicated in Fig S1. Faecal samples were homogenised in 10ml SM buffer followed by centrifugation twice at $5,000 \mathrm{~g}$ at $10^{\circ} \mathrm{C}$ for $10 \mathrm{mins}$ and filtration through a $0.45 \mu \mathrm{m}$ syringe filter to remove particulates and bacterial cells. $\mathrm{NaCl}(0.5 \mathrm{M}$ final concentration; Sigma) and 10\% w/v polyethylene glycol (PEG-8000; Sigma) were added to the resulting filtrate and incubated at $4^{\circ} \mathrm{C}$ overnight. Following centrifugation at $5,000 \mathrm{~g}$ at $4^{\circ} \mathrm{C}$ for 20 mins, the pellet was resuspended in $400 \mu \mathrm{l} \mathrm{SM}$ buffer. An equal volume of chloroform (Fisher) was added and following $30 \mathrm{sec}$ of vortexing the sample was centrifuged at 2,500g for 5 mins at RT. The aqueous top layer is retained and it was subjected to RNase I (10U final concentration; Ambion) and DNase (20U final concentration; TURBO DNA-free ${ }^{\text {TM }}$ Kit, Invitrogen) treatment in accordance with the manufacturer's guidelines. To isolate DNA, virus like particles were incubated with $20 \mu \mathrm{L}$ of $10 \%$ SDS and $2 \mu \mathrm{L}$ of proteinase $\mathrm{K}$ (Sigma, $20 \mathrm{mg} / \mathrm{mL}$ ) for $20 \mathrm{~min}$ at $56^{\circ} \mathrm{C}$, prior to lysis by the addition of $100 \mu \mathrm{L}$ of Phage Lysis Buffer (4.5 M guanidine thiocyanate; $45 \mathrm{mM}$ sodium citrate; $250 \mathrm{mM}$ sodium lauroyl sarcosinate; $562.5 \mathrm{mM} \beta$-mercaptoethanol; $\mathrm{pH} 7.0$ ) with incubation at $65^{\circ} \mathrm{C}$ for $10 \mathrm{~min}$. Viral DNA was purified by two treatments with an equal volume of phenol:chloroform:isoamyl alcohol (25:24:1) and passing the resulting purified DNA through a QIAGEN Blood and Tissue Purification Kit and eluting samples in $50 \mu \mathrm{L}$ of AE Buffer. In study 1 the viral DNA was used 
directly for Nextera XT library preparation (Illumina) as described by the manufacturer. In Study 2 the DNA concentrations were equalised prior to amplification using an Illustra GenomiPhi V2 kit (GE Healthcare). Amplifications of purified viral DNA was performed in triplicate on all samples as described by the manufacturer. Subsequently, an equal volume of each amplification and an equal volume of the original viral DNA purification were pooled together and used for paired-end Nextera XT library preparation. All samples were sequenced on an Illumina MiSeq at GATC in Germany.

\section{Analysis of virome sequencing data}

The quality of the raw reads was visualized with FastQC v0.11.3. Nextera adapters were removed with cutadapt v1.9.1 [37] followed by read trimming and filtering with Trimmomatic v0.36 [38] to ensure a minimum length of 60 , maximum length of 250 , and a sliding window that cuts a read once the average quality in a window size of 4 follows below a Phred score of 30. Reads were then assembled with the metaSPAdes assembler [39]. In order for a contig to be included in the final analysis it must have been at least $5 \mathrm{~kb}$ in length, then either detected as viral by Virsorter [40] in the virome decontamation mode, or had a significant BLAST hit (95\% identity over $95 \%$ of the length) to a genome in RefSeq Virus, or had no significant BLAST hits (any alignment length with an e-value greater than 1e-10) against nt. This allowed us to include known viruses, putative viruses predicted by virsorter and completely novel viral sequences not yet included in any database. The quality filtered reads were then aligned to this contig set using bowtie2 v2.1.0 [41] using the end to end alignment mode. A count table was generated with samtools v0.1.19 which was then imported into R v3.3.0 where the relative abundance of contigs (labelled as putative viruses) was plotted using ggplot2 v2.2.1.

\section{List of Abbreviations}

FVT - faecal virome transplantation; FFT - fecal filtrate transplant; FMT- faecal microbial transplantation; PCOA - principle co-ordinate analysis; IBD- inflammatory bowel disease; HIV - human immunodeficiency virus. 


\section{Declarations}

\section{Ethics approval and consent to participate}

All procedures involving animals were approved by the Irish Department of Health and Children and performed by an individual authorised to do so under licence number B100/3729.

\section{Consent for publication}

All authors consent to this publication.

\section{Availability of data and material}

All sequence data used in the analyses were deposited in the Sequence read Archive (SRA) (http://www.ncbi.nlm.nih.gov/sra) under BioProject PRJNA385256 for the 16S rRNA sequence data and BioProject PRJNA385134 for the virome sequence data. Sample IDs, meta data and corresponding accession numbers are summarized in supplementary table S7. All raw count tables, $16 \mathrm{~S}$ taxonomic assignments and $\mathrm{R}$ code used for the analysis are available at https://figshare.com/s/eb1666b10037656b987d

\section{Competing interests}

The authors declare that they have no competing interests

\section{Funding}

This publication has emanated from research conducted with the financial support of Science Foundation Ireland (SFI) under Grant Number SFI/12/RC/2273.

\section{Authors' contributions}

Conceived and supervised the study: $\mathrm{CH}$, and RR. Designed the experiments: $\mathrm{MD}, \mathrm{CH}$, and RR. Performed the experiments: PC, MD and LD. Analyzed the data: LD, FR, MD, VV, and AM. Wrote the paper: LD, FR, RR and $\mathrm{CH}$.

\section{Acknowledgements}

Not applicable 


\section{Bibliography}

1. Lepage $P$, Leclerc $M C$, Joossens $M$, Mondot S, Blottière HM, Raes J, Ehrlich D, Doré J: A metagenomic insight into our gut's microbiome. Gut 2013, 62(1):146-158.

2. Mills S, Shanahan F, Stanton C, Hill C, Coffey A, Ross RP: Movers and shakers. Gut Microbes 2013, 4(1):4-16.

3. Carding SR, Davis N, Hoyles L: The human intestinal virome in health and disease. Alimentary pharmacology \& therapeutics 2017, 46(9):800-815.

4. Sonnenburg JL, Chen CTL, Gordon JI: Genomic and Metabolic Studies of the Impact of Probiotics on a Model Gut Symbiont and Host. PLOS Biol 2006, 4(12):e413.

5. Samuel BS, Gordon JI: A humanized gnotobiotic mouse model of host-archaealbacterial mutualism. Proceedings of the National Academy of Sciences 2006, 103(26):10011-10016.

6. Chassard C, Bernalier-Donadille $A: \mathbf{H 2}$ and acetate transfers during xylan fermentation between a butyrate-producing xylanolytic species and hydrogenotrophic microorganisms from the human gut. FEMS microbiology letters 2006, 254(1):116-122.

7. Lozupone CA, Stombaugh JI, Gordon JI, Jansson JK, Knight R: Diversity, stability and resilience of the human gut microbiota. Nature 2012, 489(7415):220-230.

8. Dalmasso M, Hill C, Ross RP: Exploiting gut bacteriophages for human health. Trends in microbiology 2014, 22(7):399-405.

9. Dethlefsen L, McFall-Ngai M, Relman DA: An ecological and evolutionary perspective on human-microbe mutualism and disease. Nature 2007, 449(7164):811-818.

10. Ley RE, Peterson DA, Gordon JI: Ecological and Evolutionary Forces Shaping Microbial Diversity in the Human Intestine. Cell 2006, 124(4):837-848.

11. Windey K, De Preter V, Verbeke K: Relevance of protein fermentation to gut health. Molecular Nutrition \& Food Research 2012, 56(1):184-196.

12. Peterson CT, Sharma V, Elmén L, Peterson SN: Immune homeostasis, dysbiosis and therapeutic modulation of the gut microbiota. Clinical \& Experimental Immunology 2015, 179(3):363-377.

13. Tamboli CP, Neut C, Desreumaux P, Colombel JF: Dysbiosis in inflammatory bowel disease. Gut 2004, 53(1):1-4.

14. Yan AW, E. Fouts D, Brandl J, Stärkel P, Torralba M, Schott E, Tsukamoto H, E. Nelson $\mathrm{K}, \mathrm{A}$. Brenner D, Schnabl B: Enteric dysbiosis associated with a mouse model of alcoholic liver disease. Hepatology 2011, 53(1):96-105. 
15. Kang S, Denman SE, Morrison M, Yu Z, Dore J, Leclerc M, McSweeney CS: Dysbiosis of fecal microbiota in Crohn's disease patients as revealed by a custom phylogenetic microarray. Inflammatory Bowel Diseases 2010, 16(12):2034-2042.

16. Hofer U, Speck RF: Disturbance of the gut-associated lymphoid tissue is associated with disease progression in chronic HIV infection. In: Seminars in immunopathology: 2009. Springer: 257-266.

17. Penders J, Stobberingh EE, Brandt PAvd, Thijs C: The role of the intestinal microbiota in the development of atopic disorders. Allergy 2007, 62(11):1223-1236.

18. Collins SM, Bercik P: The Relationship Between Intestinal Microbiota and the Central Nervous System in Normal Gastrointestinal Function and Disease. Gastroenterology 2009, 136(6):2003-2014.

19. Clemente JC, Pehrsson EC, Blaser MJ, Sandhu K, Gao Z, Wang B, Magris M, Hidalgo G, Contreras M, Noya-Alarcón Ó: The microbiome of uncontacted Amerindians. Science advances 2015, 1(3):e1500183.

20. Sullivan $\AA$, Barkholt L, Nord CE: Lactobacillus acidophilus, Bifidobacterium lactis and Lactobacillus F19 prevent antibiotic-associated ecological disturbances of Bacteroides fragilis in the intestine. Journal of Antimicrobial Chemotherapy 2003, 52(2):308-311.

21. Kajander K, Myllyluoma E, Rajilić-Stojanović $M$, KyrÖNpalo $S$, Rasmussen $M$, $J \ddot{R}$ venp $\ddot{A} \mathrm{~A}$ S, Zoetendal EG, De Vos WM, Vapaatalo H, Korpela R: Clinical trial: multispecies probiotic supplementation alleviates the symptoms of irritable bowel syndrome and stabilizes intestinal microbiota. Alimentary Pharmacology \& Therapeutics 2008, 27(1):48-57.

22. Walker AW, Lawley TD: Therapeutic modulation of intestinal dysbiosis. Pharmacological Research 2013, 69(1):75-86.

23. Glenn $G$, Roberfroid M: Dietary modulation of the human colonic microbiota: introducing the concept of prebiotics. J nutr 1995, 125:1401-1412.

24. Kelly CR, Kahn S, Kashyap P, Laine L, Rubin D, Atreja A, Moore T, Wu G: Update on Fecal Microbiota Transplantation 2015: Indications, Methodologies, Mechanisms, and Outlook. Gastroenterology 2015, 149(1):223-237.

25. Cammarota G, laniro G, Tilg H, Rajilić-Stojanović M, Kump P, Satokari R, Sokol H, Arkkila $\mathrm{P}$, Pintus $\mathrm{C}$, Hart $\mathrm{A}$ et al: European consensus conference on faecal microbiota transplantation in clinical practice. Gut 2017.

26. Colman RJ, Rubin DT: Fecal Microbiota Transplantation as Therapy for Inflammatory Bowel Disease: A Systematic Review and Meta-Analysis. Journal of Crohn's \& colitis 2014, 8(12):1569-1581.

27. Reyes A, Wu M, McNulty NP, Rohwer FL, Gordon Jl: Gnotobiotic mouse model of phage-bacterial host dynamics in the human gut. Proceedings of the National Academy of Sciences 2013, 110(50):20236-20241.

28. Klindworth A, Pruesse E, Schweer T, Peplies J, Quast C, Horn M, Glöckner FO: Evaluation of general 16S ribosomal RNA gene PCR primers for classical and nextgeneration sequencing-based diversity studies. Nucleic acids research 2012:gks808.

29. Magoč T, Salzberg SL: FLASH: fast length adjustment of short reads to improve genome assemblies. Bioinformatics 2011, 27(21):2957-2963.

30. Edgar RC: UPARSE: highly accurate OTU sequences from microbial amplicon reads. Nature methods 2013, 10(10):996-998.

31. Caporaso JG, Kuczynski J, Stombaugh J, Bittinger K, Bushman FD, Costello EK, Fierer N, Peña AG, Goodrich JK, Gordon JI: QIIME allows analysis of high-throughput community sequencing data. Nature methods 2010, 7(5):335-336. 
32. Schloss PD, Westcott SL, Ryabin T, Hall JR, Hartmann M, Hollister EB, Lesniewski RA, Oakley BB, Parks DH, Robinson $\mathrm{CJ}$ : Introducing mothur: open-source, platformindependent, community-supported software for describing and comparing microbial communities. Applied and environmental microbiology 2009, 75(23):75377541.

33. Allard G, Ryan FJ, Jeffery IB, Claesson MJ: SPINGO: a rapid species-classifier for microbial amplicon sequences. BMC bioinformatics 2015, 16(1):324.

34. Price MN, Dehal PS, Arkin AP: FastTree: computing large minimum evolution trees with profiles instead of a distance matrix. Molecular biology and evolution 2009, 26(7):1641-1650.

35. Love $\mathrm{MI}$, Huber $\mathrm{W}$, Anders $\mathrm{S}$ : Moderated estimation of fold change and dispersion for RNA-seq data with DESeq2. Genome biology 2014, 15(12):550.

36. Furet J-P, Firmesse O, Gourmelon M, Bridonneau C, Tap J, Mondot S, Doré J, Corthier $\mathrm{G}$ : Comparative assessment of human and farm animal faecal microbiota using real-time quantitative PCR. FEMS microbiology ecology 2009, 68(3):351-362.

37. Martin $\mathrm{M}$ : Cutadapt removes adapter sequences from high-throughput sequencing reads. EMBnet journal 2011, 17(1):pp. 10-12.

38. Bolger $A M$, Lohse $M$, Usadel $B$ : Trimmomatic: a flexible trimmer for Illumina sequence data. Bioinformatics 2014:btu170.

39. Nurk S, Meleshko D, Korobeynikov A, Pevzner PA: metaSPAdes: a new versatile metagenomic assembler. Genome Research 2017:gr. 213959.213116.

40. Roux S, Enault F, Hurwitz BL, Sullivan MB: VirSorter: mining viral signal from microbial genomic data. PeerJ 2015, 3:e985.

41. Langmead B, Salzberg SL: Fast gapped-read alignment with Bowtie 2. Nature methods 2012, 9(4):357-359.

42. Dublanchet $A$, Fruciano $\mathrm{E}$ : Brève histoire de la phagothérapie. Médecine et maladies infectieuses 2008, 38(8):415-420.

43. Letarov A, Kulikov E: The bacteriophages in human-and animal body-associated microbial communities. Journal of applied microbiology 2009, 107(1):1-13.

44. Sulakvelidze A, Kutter E: 14 Bacteriophage Therapy in Humans. Bacteriophages: biology and applications 2004:381.

45. Wittebole X, De Roock S, Opal SM: A historical overview of bacteriophage therapy as an alternative to antibiotics for the treatment of bacterial pathogens. Virulence 2014, 5(1):226-235.

46. Weinbauer MG: Ecology of prokaryotic viruses. FEMS microbiology reviews 2004, 28(2):127-181.

47. Draper L, Ryan F, Smith M, Jalanka J, Mattila E, Arkkila P, Ross R, Satokari R, Hill C: Long-term colonisation with donor bacteriophages following successful faecal microbial transplantation. Microbiome 2018, 6(1):220.

48. Chehoud C, Dryga A, Hwang Y, Nagy-Szakal D, Hollister EB, Luna RA, Versalovic J, Kellermayer R, Bushman FD: Transfer of viral communities between human individuals during fecal microbiota transplantation. MBio 2016, 7(2):e00322-00316.

49. Ott SJ, Waetzig GH, Rehman A, Moltzau-Anderson J, Bharti R, Grasis JA, Cassidy L, Tholey A, Fickenscher H, Seegert D: Efficacy of Sterile Fecal Filtrate Transfer for Treating Patients With Clostridium difficile Infection. Gastroenterology 2016.

50. Watanakunakorn C: Penicillin combined with gentamicin or streptomycin: synergism against enterococci. Journal of infectious Diseases 1971, 124(6):581-586. 
51. Moellering RC, Medoff G, Leech I, Wennersten C, Kunz L: Antibiotic synergism against Listeria monocytogenes. Antimicrobial agents and chemotherapy 1972, 1(1):30-34.

52. Sekirov I, Tam NM, Jogova M, Robertson ML, Li Y, Lupp C, Finlay BB: AntibioticInduced Perturbations of the Intestinal Microbiota Alter Host Susceptibility to Enteric Infection. Infection and Immunity 2008, 76(10):4726-4736.

53. Raum E, Lietzau S, Von Baum H, Marre R, Brenner H: Changes in Escherichia coli resistance patterns during and after antibiotic therapy: a longitudinal study among outpatients in Germany. Clinical Microbiology and Infection 2008, 14(1):41-48.

54. Livermore DM: beta-Lactamases in laboratory and clinical resistance. Clinical microbiology reviews 1995, 8(4):557-584.

55. Gu S, Chen D, Zhang J-N, Lv X, Wang K, Duan L-P, Nie Y, Wu X-L: Bacterial community mapping of the mouse gastrointestinal tract. PloS one 2013, 8(10):e74957.

56. Bojanova DP, Bordenstein SR: Fecal transplants: what is being transferred? PLOS Biol 2016, 14(7):e1002503.

57. De Paepe $M$, Leclerc $M$, Tinsley $C R$, Petit M-A: Bacteriophages: an underestimated role in human and animal health? Frontiers in cellular and infection microbiology 2014, 4:39.

58. Hoyles L, McCartney AL, Neve H, Gibson GR, Sanderson JD, Heller KJ, van Sinderen D: Characterization of virus-like particles associated with the human faecal and caecal microbiota. Research in microbiology 2014, 165(10):803-812.

59. Daillère R, Vétizou $M$, Waldschmitt N, Yamazaki T, Isnard C, Poirier-Colame V, Duong $\mathrm{CP}$, Flament $\mathrm{C}$, Lepage $\mathrm{P}$, Roberti MP: Enterococcus hirae and barnesiella intestinihominis facilitate cyclophosphamide-induced therapeutic immunomodulatory effects. Immunity 2016, 45(4):931-943.

60. Zhang X, McDaniel AD, Wolf LE, Keusch GT, Waldor MK, Acheson DW: Quinolone antibiotics induce Shiga toxin-encoding bacteriophages, toxin production, and death in mice. Journal of Infectious Diseases 2000, 181(2):664-670.

61. Meessen-Pinard M, Sekulovic O, Fortier L-C: Evidence of in vivo prophage induction during Clostridium difficile infection. Applied and environmental microbiology 2012, 78(21):7662-7670.

62. Matos RC, Lapaque N, Rigottier-Gois L, Debarbieux L, Meylheuc T, Gonzalez-Zorn B, Repoila $F$, de Fatima Lopes $M$, Serror $P$ : Enterococcus faecalis prophage dynamics and contributions to pathogenic traits. PLoS Genet 2013, 9(6):e1003539.

63. Maiques E, Úbeda C, Campoy S, Salvador N, Lasa Í, Novick RP, Barbé J, Penadés JR: $\boldsymbol{\beta}$ Lactam antibiotics induce the SOS response and horizontal transfer of virulence factors in Staphylococcus aureus. Journal of bacteriology 2006, 188(7):2726-2729.

64. Thingstad T, Lignell R: Theoretical models for the control of bacterial growth rate, abundance, diversity and carbon demand. Aquatic Microbial Ecology 1997, 13(1):19-27.

65. Thingstad TF: Elements of a theory for the mechanisms controlling abundance, diversity, and biogeochemical role of lytic bacterial viruses in aquatic systems. Limnology and Oceanography 2000, 45(6):1320-1328.

66. Kashyap PC, Marcobal A, Ursell LK, Larauche M, Duboc H, Earle KA, Sonnenburg ED, Ferreyra JA, Higginbottom SK, Million M: Complex interactions among diet, gastrointestinal transit, and gut microbiota in humanized mice. Gastroenterology 2013, 144(5):967-977. 
67. Reyes A, Haynes M, Hanson N, Angly FE, Heath AC, Rohwer F, Gordon J: Viruses in the faecal microbiota of monozygotic twins and their mothers. Nature 2010, 466(7304):334-338.

68. Reyes A, Semenkovich NP, Whiteson K, Rohwer F, Gordon Jl: Going viral: nextgeneration sequencing applied to phage populations in the human gut. Nature Reviews Microbiology 2012, 10(9):607-617.

69. Minot S, Bryson A, Chehoud C, Wu GD, Lewis JD, Bushman FD: Rapid evolution of the human gut virome. Proceedings of the National Academy of Sciences 2013, 110(30):12450-12455. 


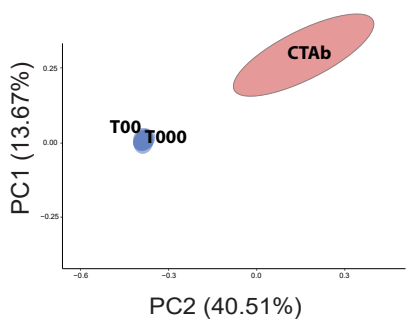

Pre-Treatment

Post Ab Treatment

FVT Mice

Control Mice

Gavage $+12 \mathrm{~h}$

Gavage + 24 h

Gavage + 36 h

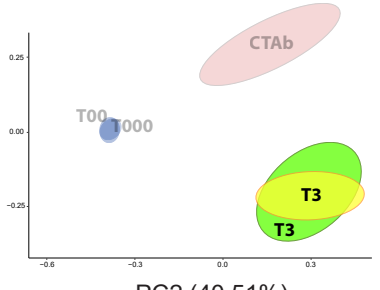

PC2 (40.51\%)

PC2 (40.51\%)

T2

PC2 (40.51\%)

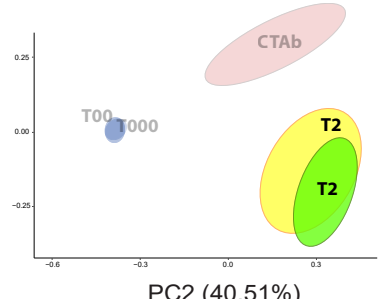

$$
\text { (1) }
$$
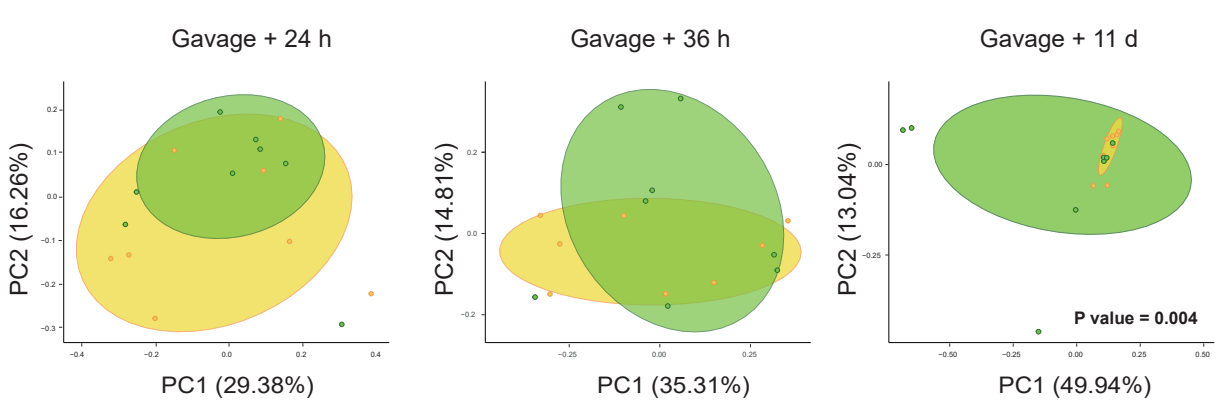

Figure 1- PCoA plots of unweighted UniFrac distances for Study 1 (A). Ellipses represent $70 \%$ confidence intervals. A UniFrac PERMANOVA test was performed with the Adonis function to determine the statistical differences between FVT and Control mice (Model formula = antibiotic treatment timepoint + Phage/control status), the resulting PCoA plots and $\mathrm{P}$ values are displayed (B). 


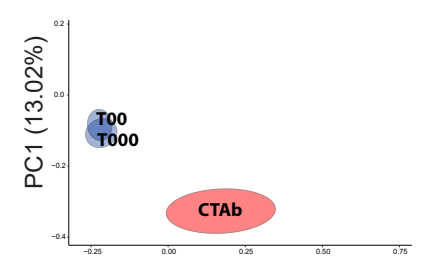

Gavage $2+4 d$

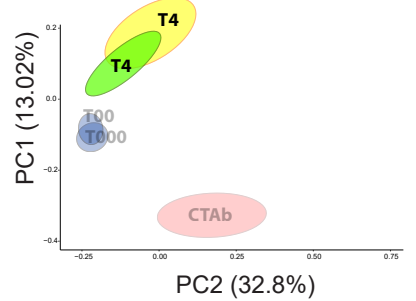

B
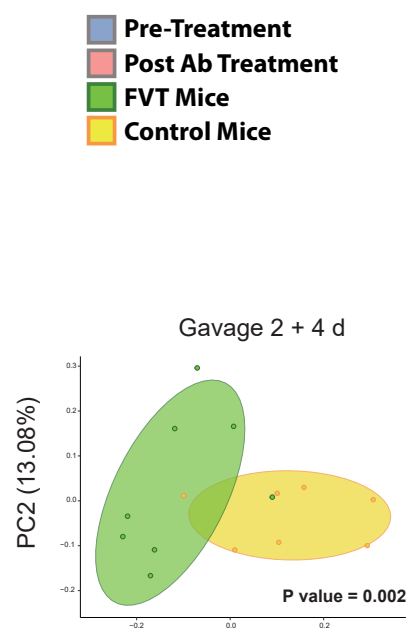

PC1 (24.93\%)

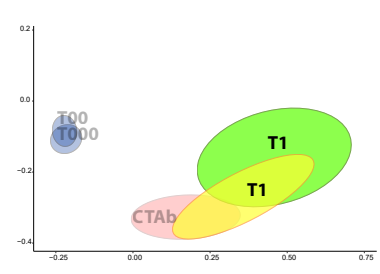

Gavage $2+7 d$

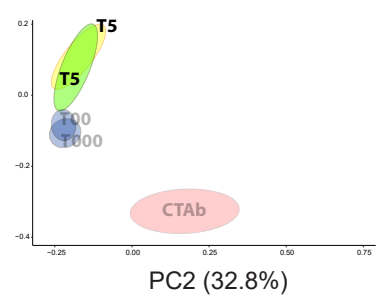

Gavage $1+24$ h

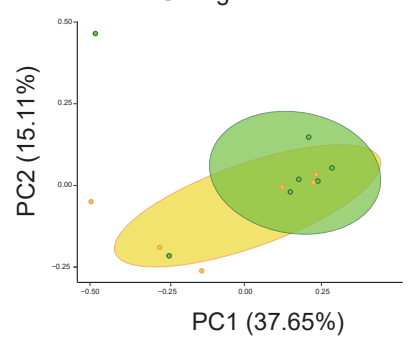

Gavage $2+7 d$

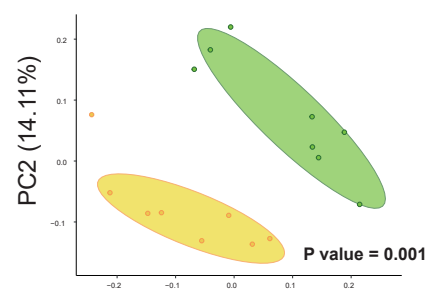

PC1 (20.68\%)

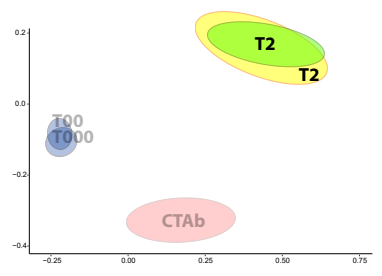

Gavage $2+11 \mathrm{~d}$

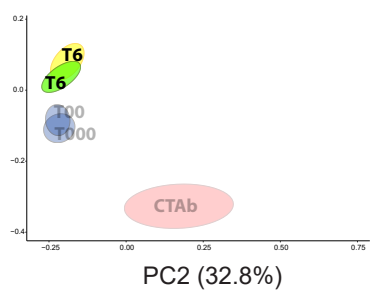

Gavage $1+4 d$

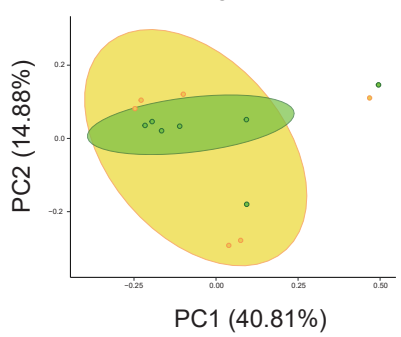

Gavage $2+11 d$

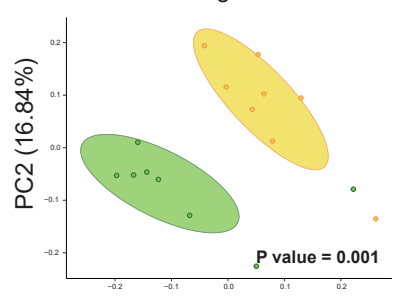

PC1 (22.91\%)

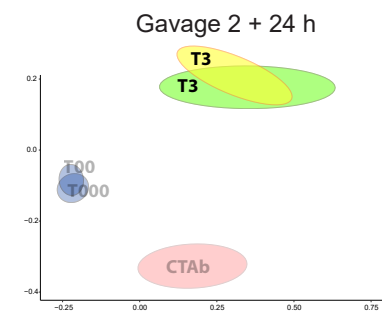

Gavage $2+11$ d (cecum)

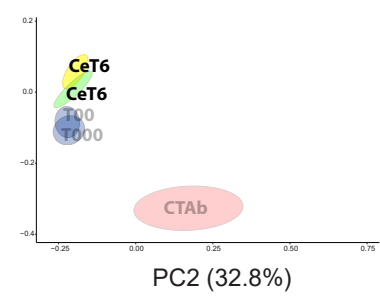

Gavage $2+24 \mathrm{~h}$

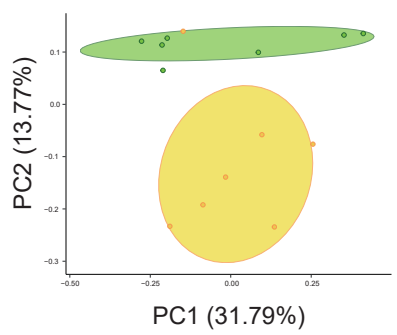

Gavage $2+11 \mathrm{~d}$ (cecum)

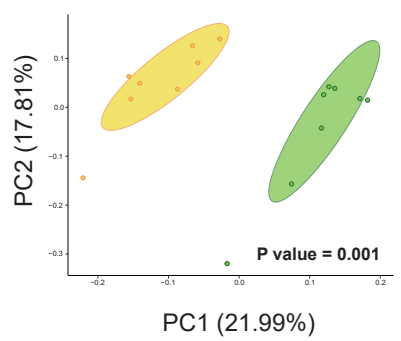

Figure 2- PCoA plots of unweighted UniFrac distances for Study 2 (A). Ellipses represent $70 \%$ confidence intervals. A UniFrac PERMANOVA test was performed with the Adonis function to determine the statistical differences between FVT and Control mice (Model formula = antibiotic treatment timepoint + Phage/control status), the resulting PCoA plots and $\mathrm{P}$ values are displayed (B). 


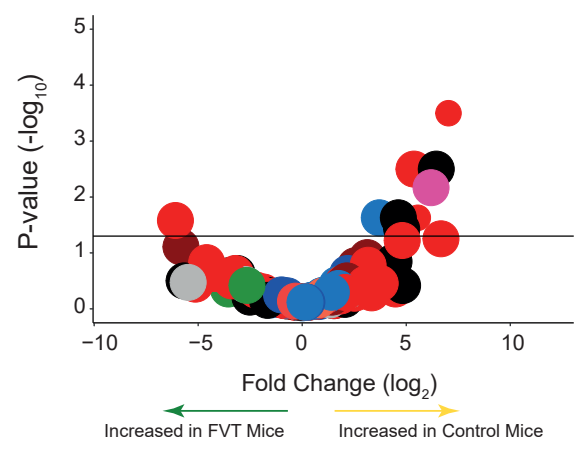

\section{Family}

- Bacteroidaceae

Bifidobacteriaceae

Desulfovibrionaceae

Enterobacteriaceae

- Lachnospiraceae

Lactobacillaceae

Other

Porphyromonadaceae

Rikenellaceae

- Ruminococcaceae

- Deferribacteraceae

- Unclassified
Normalised

Abundance

- 1st quartile

2nd quartile

3rd quartile

4th quartile

B

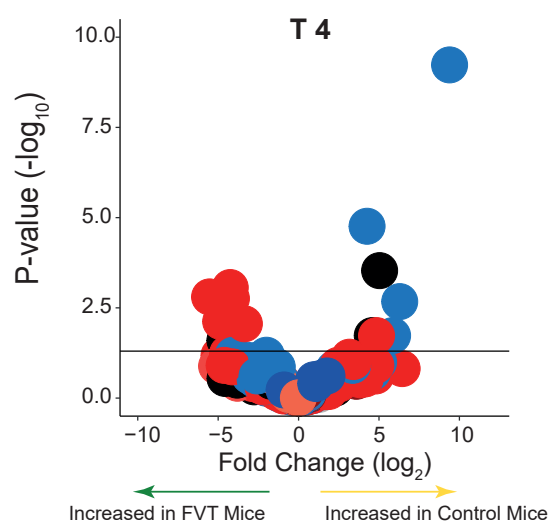

T 6

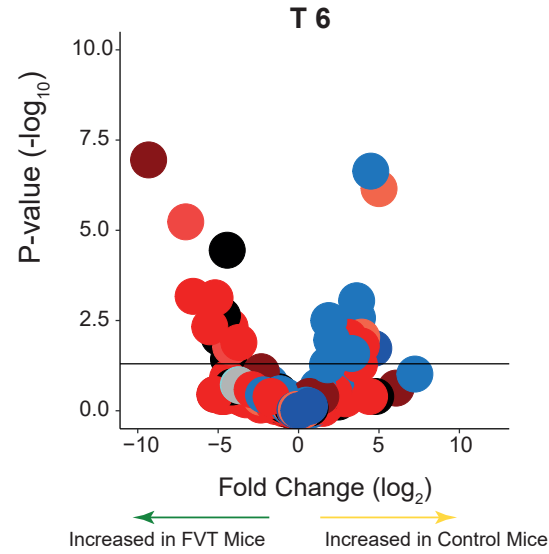

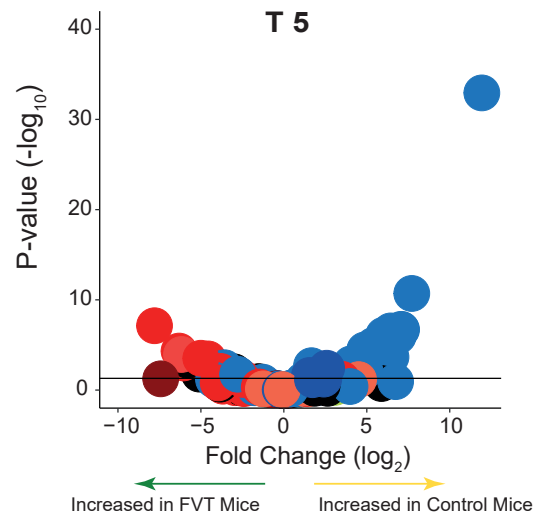

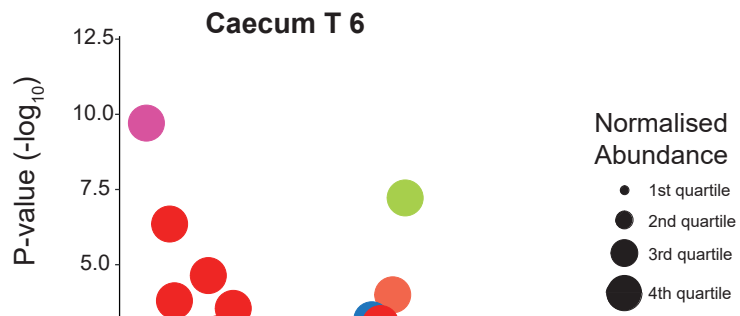

Figure 3- Volcano plots showing the results of DESeq2 which detects differentially abundant RSVs between the FVT and Control mice at each time point in Study 1 (A) and Study 2 (B). RSVs with an adjusted p-value $<0.05$ are positioned above the horizontal line. Normalised abundance is also represented. Families belonging to the phylum Firmicutes are indicated via varying shades of red, while families derived from Bacteroides are visualised in blue, additional colours are used to represent other families and phyla. 


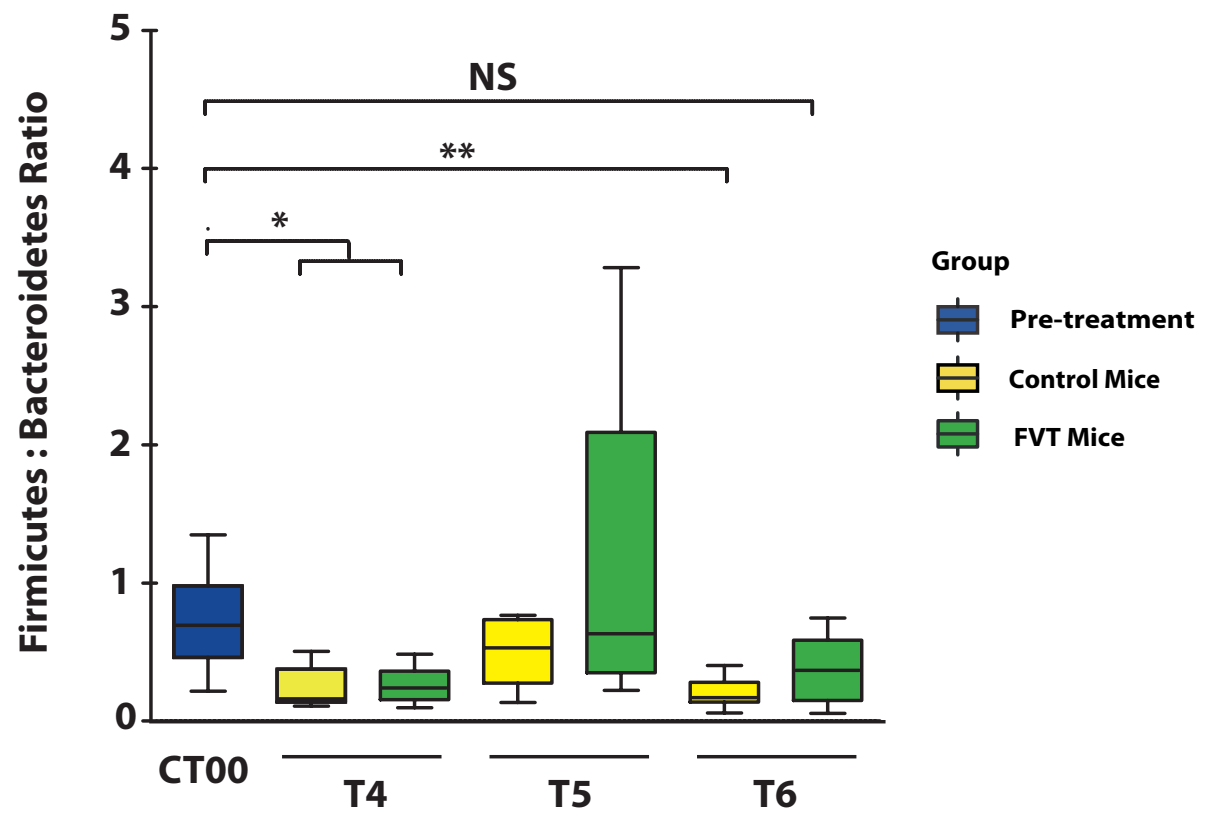

Figure 4 - Bacteroidetes Firmicutes ratio reveals that the ratio is statistically higher in FVT mice as determined via Kruskal-Wallis with Dunn's multiple comparison posttest; CT00 vs CT4/PT4: P-value <0.05; CT00 vs CT6:P-value <0.01; CT00 vs PT6: $P$-value $>0.05$ ) 

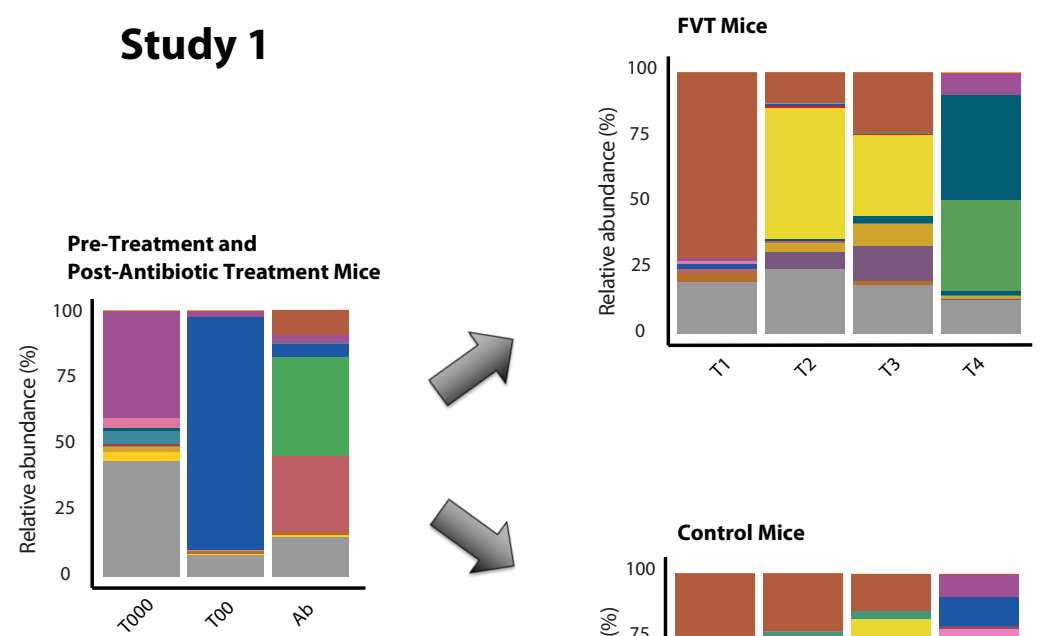

\section{Study 2}
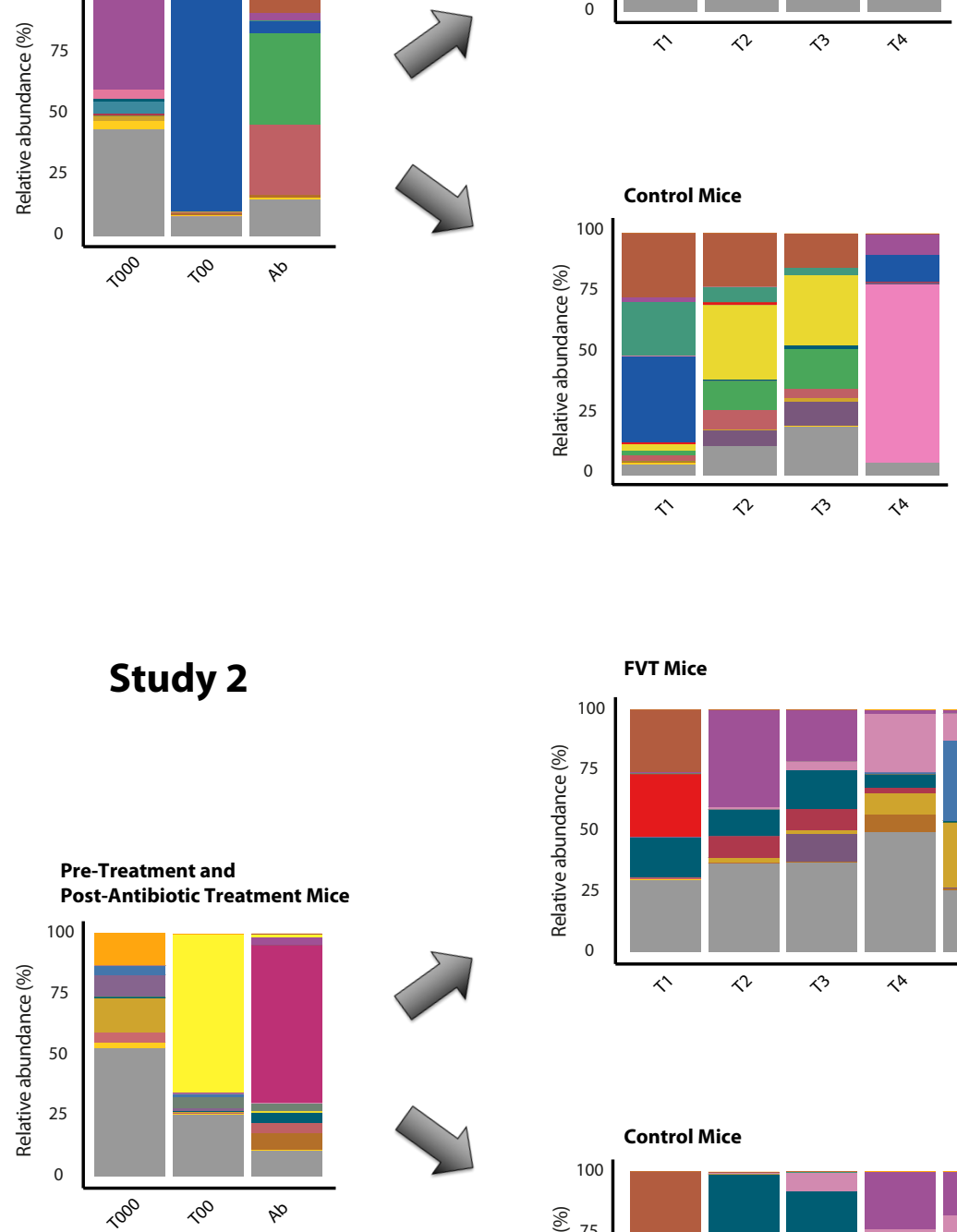

Putative Viruses

APC_pVirus_1 APC_pVirus_2 APC_pVirus_3 APC_pVirus_4

APC_pVirus_5 APC_pVirus_6 APC_pVirus_7

APC_pVirus_8 APC_pVirus_9 APC_pVirus_10 APC_pVirus_11 APC_pVirus_12 APC_pVirus_13 APC_pVirus_14 APC_pVirus_15 APC_pVirus_16 APC_pVirus_17 APC_pVirus_18 APC pVirus 19 APC_pVirus_20 APC_pVirus_21

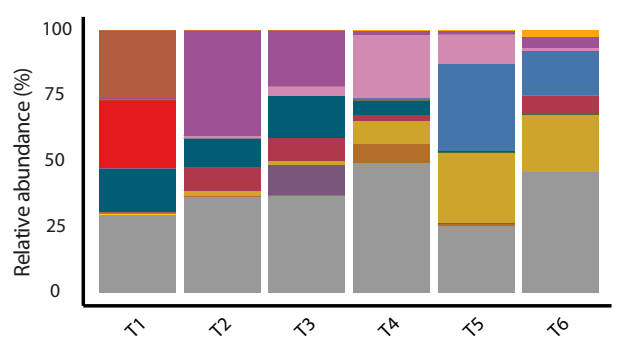

APC pVirus 22 APC_pVirus_23 APC_pVirus 24 APC_pVirus_25 APC_pVirus_26 Other
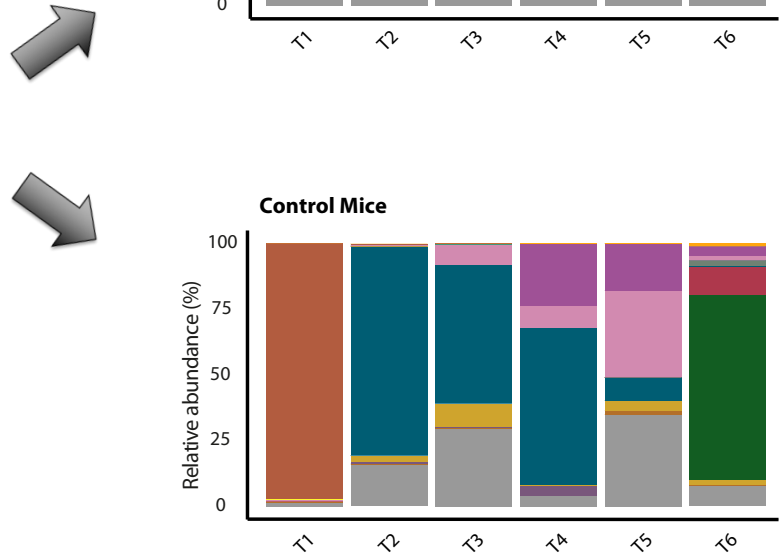

Figure 5 -Metagenomic analysis on DNA isolated from viruses extracted from murine faecal samples in Study 1 (A) and Study 2 (B). Results reflect the viromes of groups of mice, where faecal samples were combined and represent the viral pool in pre-treatment $(n=16)$, antibiotic treated $(n=16)$, Control $(n=8)$ and FVT mice $(n=8)$ at each time point. Following sequencing contigs were assembled into putative viruses and the relative abundances are represented within this bar plot. 



\section{Study 1}

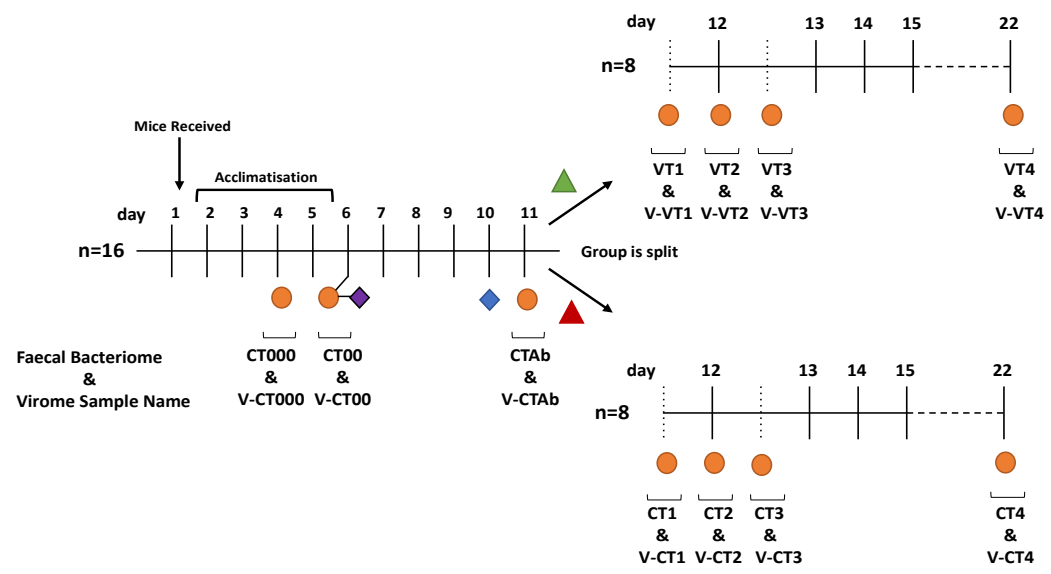

\section{Study 2}
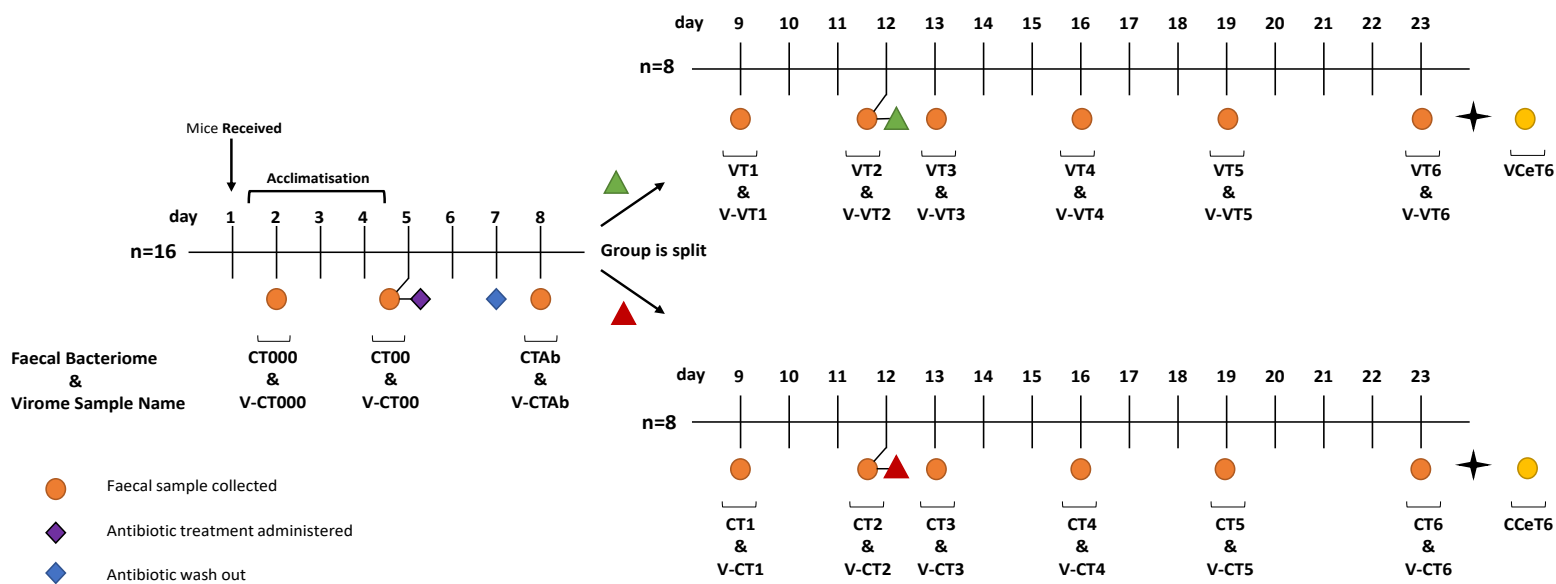

Antibiotic wash out

Gavage of viable FVT

- Gavage of heat treated FVT

+ sacrifice of animals

Caecum contents collected

Figure S1- Experimental design of Study $1(A)$ and Study $2(B)$. BALB/c mice $(n=16)$ were, after acclimatisation, administered antibiotic treatment. After a period of antibiotic wash-out the group was split into two $(n=8)$ and the mice were gavaged with an FVT, a sterile virome faecal filtrate (either viable or heat killed) that had been isolated from frozen faecal samples obtained from the mice during acclimatisation. In Study 2 (B) a second gavage was administered 4 days after the first, dotted vertical lines representing time points within a day. Each group of mice was individually caged. Each solid vertical line represents a day. Time points selected for sampling the faecal microbiota of each mouse in each treatment group are represented as circles and labelled. Samples were subjected to $16 \mathrm{~S}$ rRNA sequencing and viral metagenomic sequencing. 


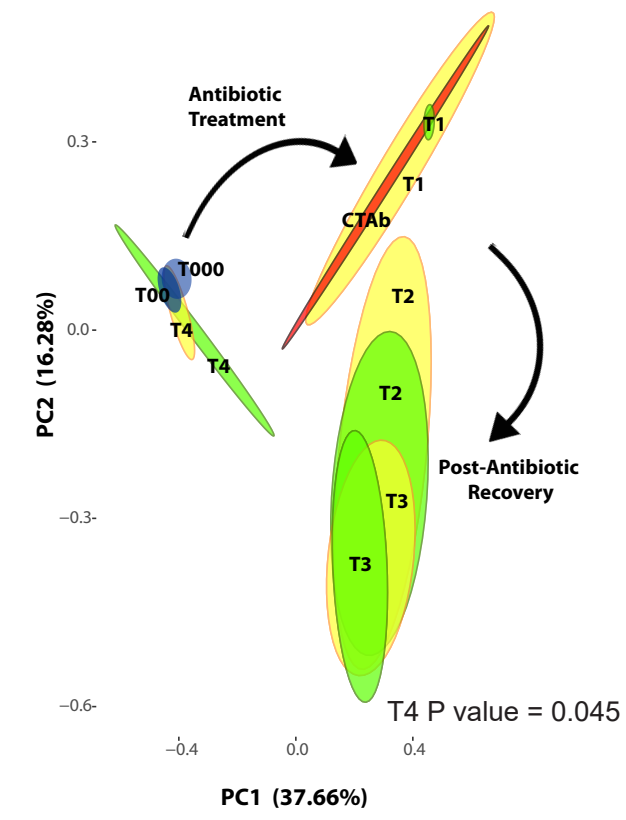

0.4- Weighted Unifrac

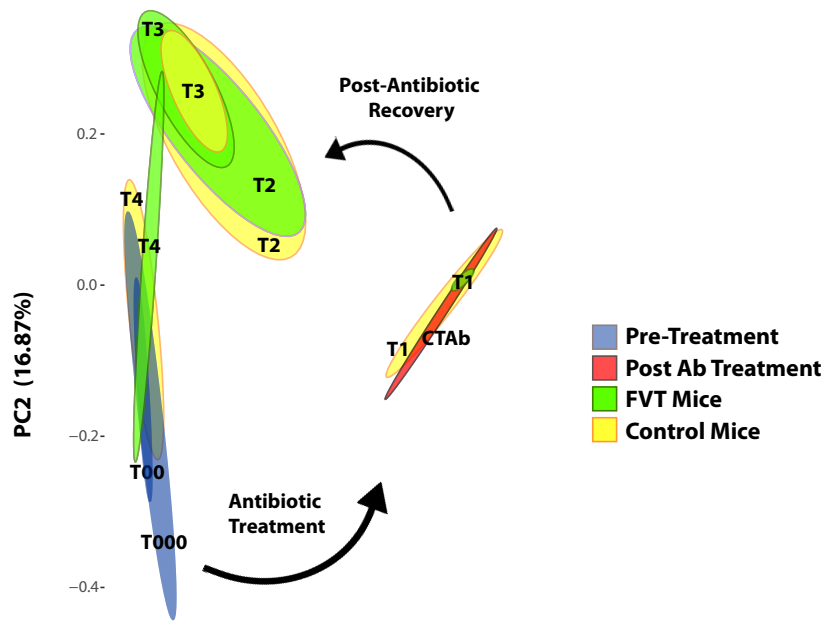

B
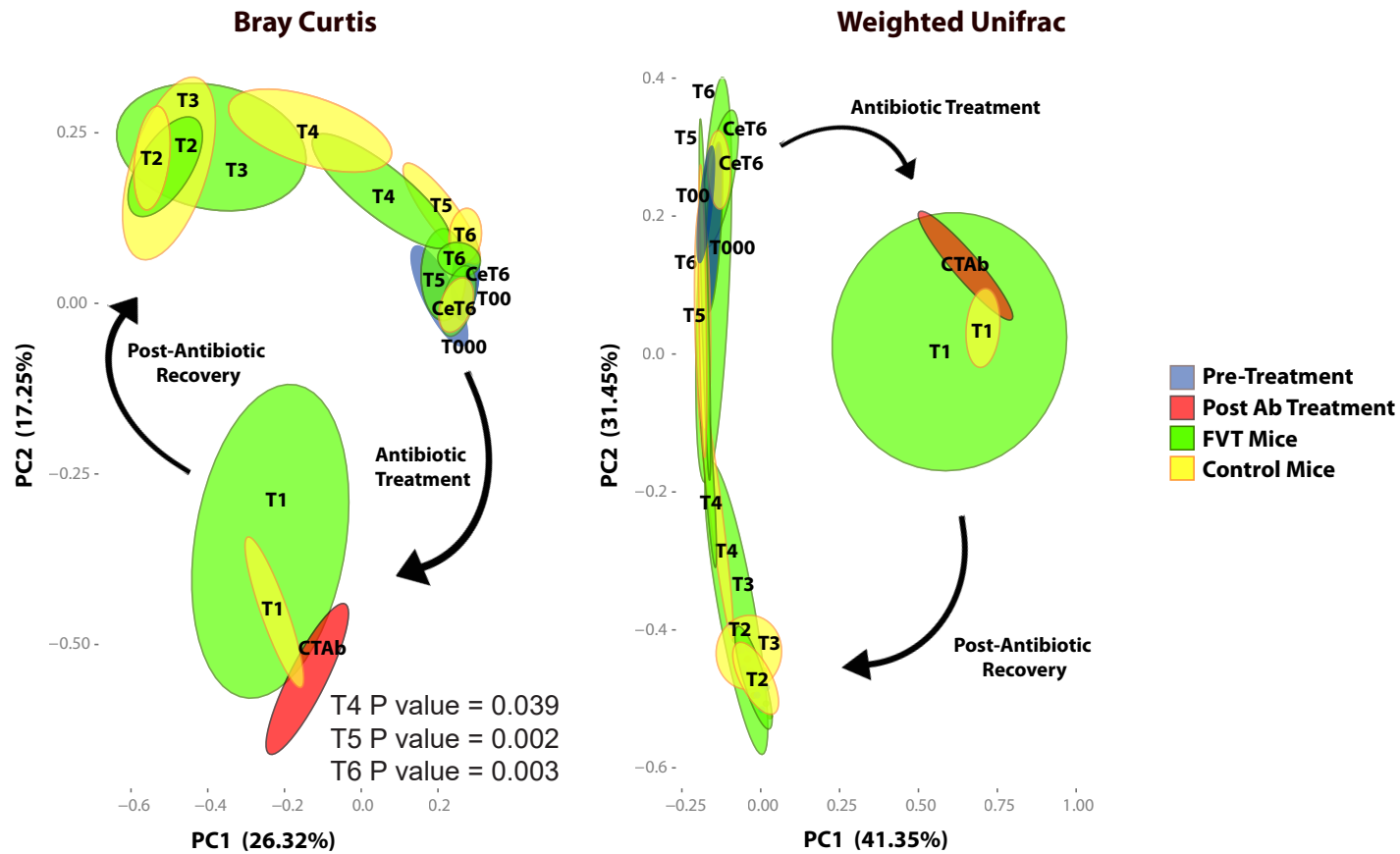

Figure S2- PCoA plots compiled using Bray Curtis and Weighted Unifrac for Study 1 (A) and Study 2 (B). Statistically significant $P$ values following UniFrac PERMANOVA analysis performed with the Adonis function to determine the statistical differences between FVT and Control mice have been inserted. 


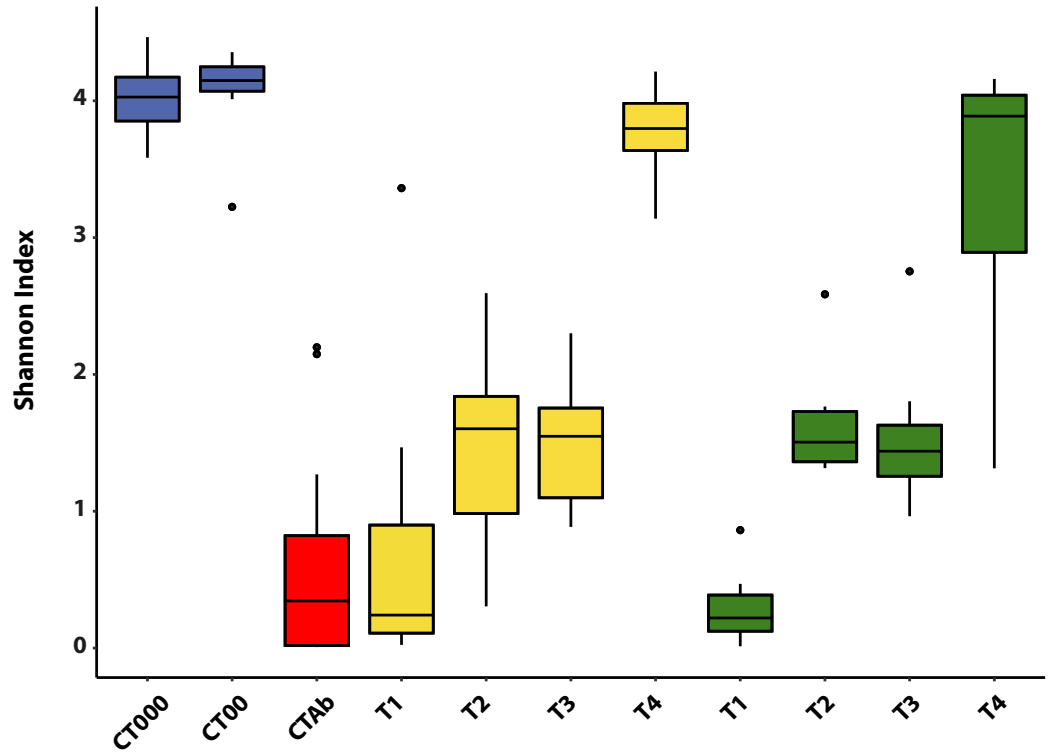

Group

Pre-treatment Post Ab treatment 追 Control Mice 官 FVT Mice

B
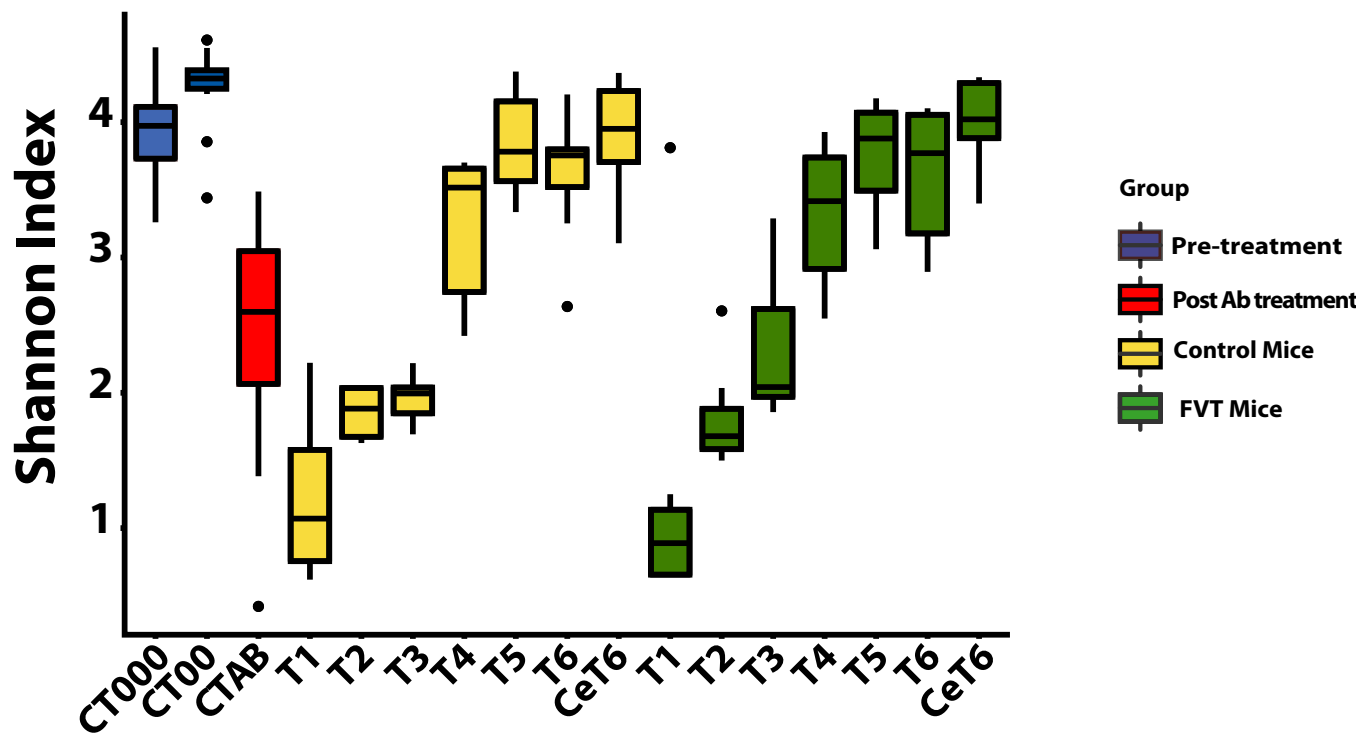

Figure S3- Shannon diversity index was used to display the bacteriome alpha diversity over time for Study 1 (A) and Study 2 (B). No statistical differences were observed in alpha diversity between FVT and Control mice at corresponding time points. 

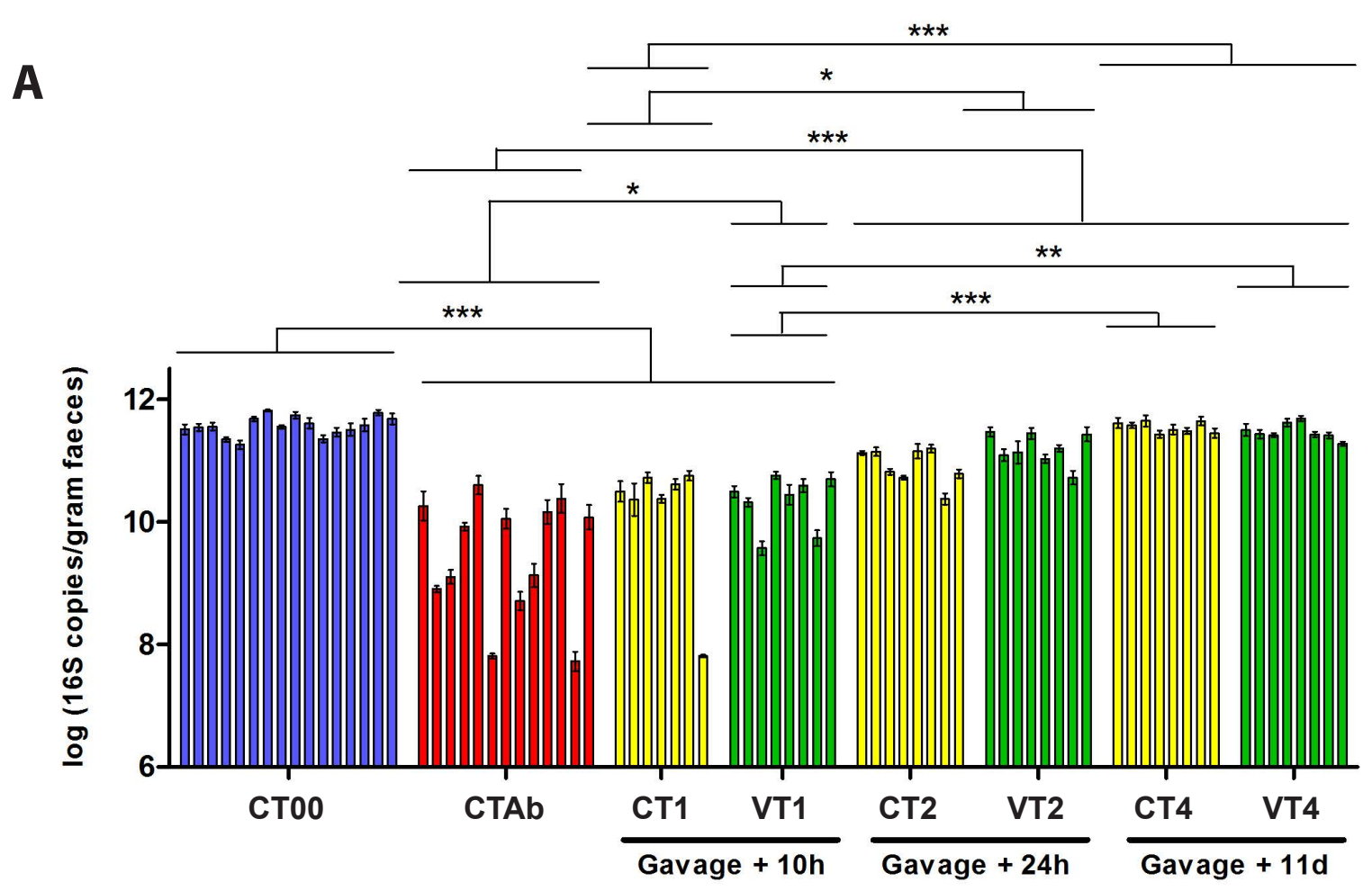

B

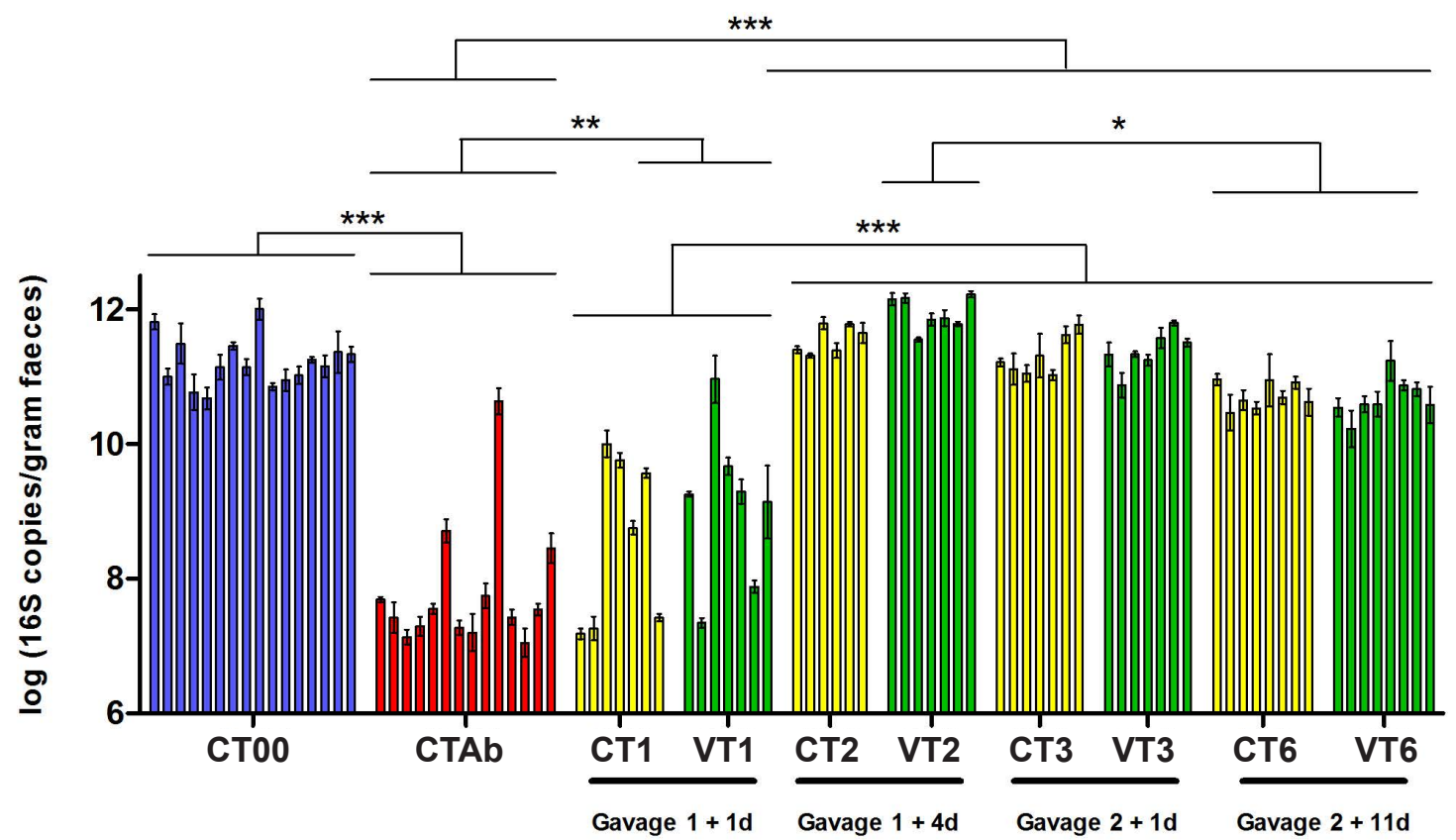

Figure S4- PPCR was used to determine the approximate bacterial cell numbers present per gram of faeces in Study 1 (A) and Study 2 (B). Bacterial cell numbers were seen to drop dramatically following antibiotic treatment in both studies. A One-Way ANOVA followed by Tukey test determined statistical significance; ${ }^{* * *} P$ value $<0.001,{ }^{* *} P$ value $<0.01,{ }^{*} P$ value $<0.05$ 
A

Phyla

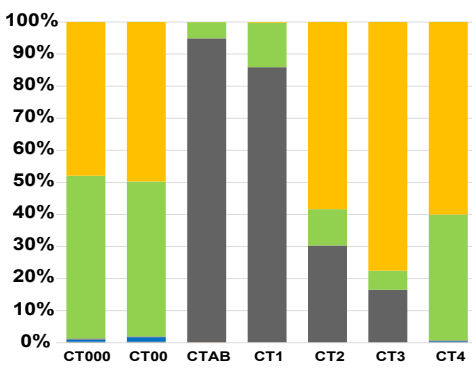

Control Mice

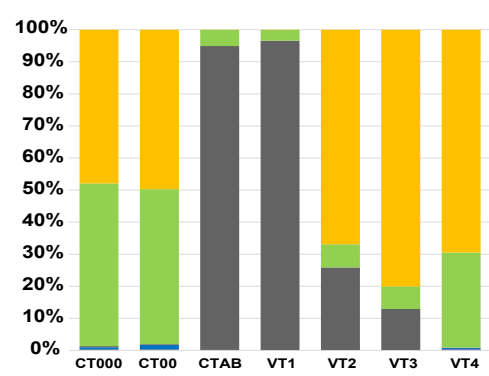

FVT Mice

B

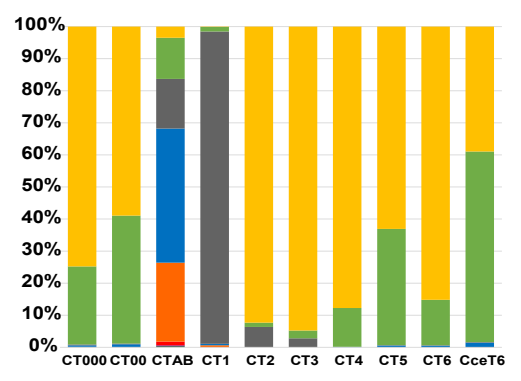

Control Mice

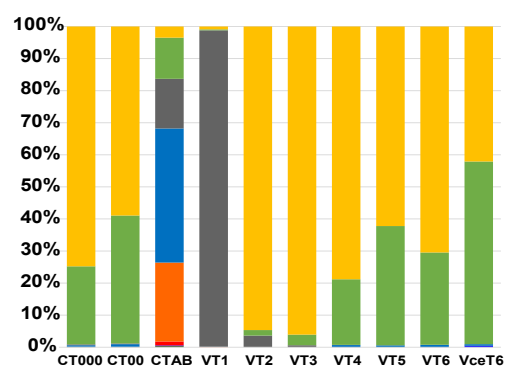

FVT Mice
Study 1

Genera

Bacteroidetes

Firmicutes

Proteobacteria

- Other

Cyanobacteria

Actinobacteria

- Tenericutes

Deferribacteres

- Saccharibacteria

Bacteroidetes

Firmicutes

Proteobacteria

- Other

Cyanobacteria

Actinobacteria

Tenericutes

Deferribacteres

- Saccharibacteria

Study 2

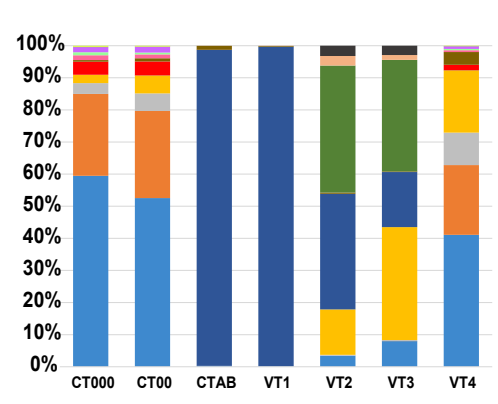

FVT Mice

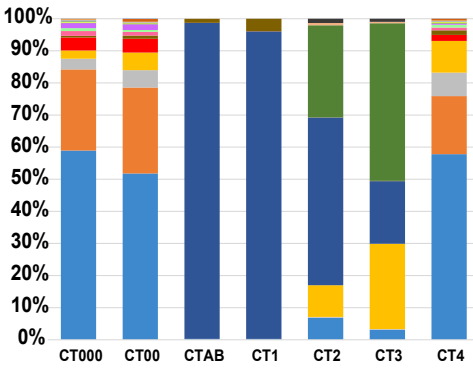

Control Mice

\section{Genera}

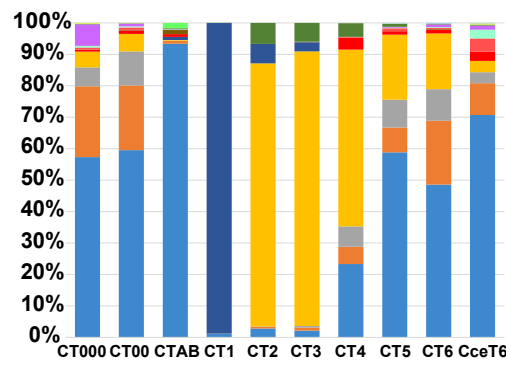

Control Mice

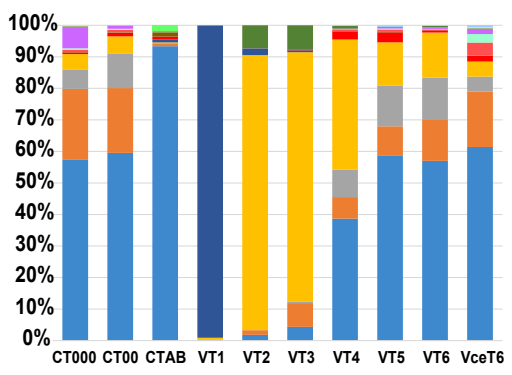

FVT Mice
Other

Alistipes

Barnesiella

Bacteroides

Escherichia/Shigella

- Clostridium XIVa

Lactobacillus

- Oscillibacter

Flavonifractor

Odoribacter

Parabacteroides

Clostridium IV

Janthinobacterium

Lachnospira

Figure S5- The abundance of different taxa visualised here at the genus level for Study 1 (A) and Study 2 (B) in mice pre-treatment (CT000 and CT00), post-antibiotic treatment (CTAB) and over time post-gavage with either viable bacteriophage (Study 1: VT1-VT4; Study 2: VT1-VceT6), or heat treated non-viable bacteriophage (Study 1: CT1-4; Study 2: CT1-CceT6). 